\title{
Interest deductibility restrictions and organizational form
}

\author{
Kay Blaufus • Marcos Kreinacke $\cdot$ Britta Mantei
}

Received: 31 January 2014/Accepted: 19 November 2014/Published online: 10 December 2014

(C) The Author(s) 2014. This article is published with open access at Springerlink.com

\begin{abstract}
Using a theoretical model for risky investment decisions, we study the effect of interest deductibility restrictions on the choice of organizational form. We analyze the two most widely used approaches: first, rules that limit the interest deductibility if the firm's leverage exceeds a specific level, and second, rules that restrict the interest deduction if the interest expenses exceed a specific percentage of the firm's earnings. Although these restrictions apply uniformly for partnerships and corporations in many countries, we find that they usually distort the choice of organizational form. We demonstrate that only leverage-based interest deductibility restrictions can in theory be modified to achieve organizational form neutrality. However, this requires a legal form dependent application or absence of dividend taxation and in any case a full loss offset which is in contrast to current law in many countries. If one considers corporate loss offset limitations, both types of interest deductibility restrictions always distort the choice of organizational form. Thus, the introduction of interest deductibility restrictions is actually in conflict with the legislators' often declared aim to design tax systems that are neutral with respect to the choice of organizational form.
\end{abstract}

Keywords Thin capitalization · Organizational form neutrality · Choice of legal form · Liability limitation

Responsible editor: Rainer Niemann (Accounting).

K. Blaufus $(\bowtie) \cdot$ M. Kreinacke $\cdot$ B. Mantei

Leibniz Universität Hannover, Hannover, Germany

e-mail: blaufus@steuern.uni-hannover.de

M. Kreinacke

e-mail: kreinacke@steuern.uni-hannover.de

B. Mantei

e-mail: mantei@steuern.uni-hannover.de 
JEL Classification $\mathrm{G} 3 \cdot \mathrm{H} 25 \cdot \mathrm{K} 34 \cdot \mathrm{M} 21$

\section{Introduction}

In most countries, dividend payments are non-deductible for tax purposes whereas interest payments are. The different tax treatment of dividends and interest can create an incentive to use debt. To combat the excessive use of debt financing, many countries recently introduced new interest deductibility restrictions (see e.g., Webber 2010). Whereas prior rules only limit the deductibility for interest on related-party debt, there is a trend to extend the deductibility restriction to all interest payments including arm's-length payments (e.g., Australia, Belgium, Denmark, Germany, and Italy). Moreover, the new rules often apply not only to corporations but also to partnerships and sole proprietorships (e.g., Australia, France, and Germany). The approaches to determine excessive debt, however, differ from country to country. Mainly two approaches are used: most thin capitalization rules limit the deductibility of interest expense if the amount of debt exceeds a specific leverage ratio. Instead of the leverage ratio, earnings-stripping rules specify an interest coverage ratio. In this case, interest expense is only deductible up to a certain percentage of the earnings before interest, taxes, depreciation, and amortization (EBITDA).

While there is a large body of research on the effect of taxes on capital structure decisions that has recently been reviewed by Feld et al. (2013), there are only a few studies investigating the economic effects of interest deductibility restrictions (IDR). Maßbaum and Sureth (2009) consider thin capitalization rules that are characterized by a given permitted debt-equity ratio and investigate its impact on firms' financing decisions using the capital structure model of Miller (1977). They show theoretically that thin capitalization rules may help explain why firms issue both debt and equity even if the former is generally privileged by the tax law. Empirical studies confirm the effectiveness of the leverage-based IDR to reduce firms' debt ratios (e.g., Overesch and Wamser 2010; Buettner et al. 2012) and indicate a negative effect on firms' real investments (Buettner et al. 2006). Moreover, also the effectiveness of the EBITDA-based IDR is studied. Maßbaum et al. (2012) use the German interest ceiling rule to theoretically study the impact on firms' capital structure choices. They find that the deduction restrictions often, but not always reduce the benefit of debt financing. Empirical evidence indicates that the German rules indeed lead to lower debt ratios and interest payments (Buslei and Simmler 2012; Dreßler and Scheuering 2012) while there is yet no evidence on a negative short-term effect on real investments (Buslei and Simmler 2012).

Although in many countries IDR are applied uniformly to partnerships and corporations, previous economic research has studied only the effect on corporations. One exception is the work of Schmidt (2010) who compares the effect of the German interest ceiling rule on the effective tax rate for partnerships and corporations using numerical examples. However, she neglects tax differences resulting from differences in liability restrictions between organizational forms and does not carry out any formal analysis. Also, the large international literature on 
how corporate taxes affect organizational form decisions (e.g., Edmark and Gordon 2013; Elschner 2013; Luna and Murray 2010) does not yet examine the impact of IDR.

The aim of the current paper is to fill this research gap by studying the effect of IDR on the choice of organizational form. Our contribution is to show that IDR not only distort capital structure and investment decisions, but, in general, also distort the choice of organizational form, even if the IDR are uniformly applied to corporations and partnerships. Only under very specific assumptions outlined in Sect. 3.1, IDR do not affect the choice of organizational form. Thus, IDR are typically in conflict with the legislators' declared aim to design tax systems that are neutral with respect to the choice of organizational form. Note that in the following analysis we do not argue for or against organizational form neutrality, rather we simply assume that the legislator aims at achieving this kind of neutrality. This assumption is in line with several statements of legislators (Wagner 2006: 101). The claim for organizational form neutrality also finds support by economic researchers estimating the efficiency losses resulting from tax systems that are non-neutral with respect to the organizational form (e.g., Gravelle and Kotlikoff 1993; Goolsbee 1998). However, we acknowledge that there is an ongoing controversial discussion about the desirability of organizational form neutrality (e.g., Wagner 2006; Ewert and Niemann 2012).

For the purpose of our study we extend a model previously used by Blaufus and Hundsdoerfer (2008) and Blaufus and Mantei (2014) to incorporate leverage-based as well as EBITDA-based IDR. In a baseline model we will assume full loss offset, full deductibility of interest expenses as well as full taxability of default gains and show that this will lead to organizational form neutrality if tax rates for both forms are identical. Integrating IDR in the model, we find opposing effects: first, a dividend effect which privileges the corporation due to the fact that IDR increase only the corporate income tax burden but not shareholders' taxes. Second, a default gain effect which arises if default gains and interest expenses are treated asymmetrically. If default gains (arising due to failure in debt redemption) are taxed to a higher extent than interest is deductible, this discriminates against the corporation. We demonstrate that organizational form neutrality can only be achieved in the case of leverage-based IDR and requires a full loss offset, a symmetric treatment of interest and default gains as well as either a legal form dependent IDR or absence of shareholder taxation which is in contrast to actual legal regulations. If we consider corporate loss offset restrictions, IDR always distort the choice of organizational form.

The remainder of this paper is organized as follows: in the next section we present the baseline model assuming full interest deductibility. Subsequently, we present the incorporation of leverage-based and EBITDA-based IDR and derive the effects on the choice of organizational form analytically. Section four extends the model with respect to corporate loss offset restrictions. In the fifth section, we provide numerical illustrations using a Monte Carlo simulation to examine the effects of changing leverage ratios, risk-free interest rates, and investment risk on tax differences between corporations and partnerships caused by IDR. The last section presents conclusions and discusses implications for tax policy and research. 


\section{Baseline model with full interest deductibility and full taxability of default gains}

We consider a one-period model under uncertainty. Risk neutral investors found a company for a unique risky investment opportunity of size $I_{0}$ at time $t=0$ and decide about its legal form $(l f)$. They can choose between a corporation $(l f=c)$ with liability limited to the invested amount and a partnership $(l f=p)$ with unlimited personal liability. We use the subscripts $c$ and $p$ to denote either legal form, and the subscript $l f$ for the general case. The real investment is financed with debt amounting to $\lambda I_{0}$ and equity amounting to $(1-\lambda) I_{0}$, with exogenous $0<\lambda \leq 1$. Without loss of generality, we scale the initial investment expenditure to $I_{0}=1$. Debt capital is offered by risk neutral creditors on a competitive capital market that is free of arbitrage. We assume that debt is offered by third-parties and exclude internal debt from our analysis. Risk-free capital is available at the risk-free interest rate $r_{f}$ and risky capital at an interest rate $i>r_{f}$.

At time $t=1$, the project results in a gross return of uncertain cash flows $x \geq 0$, and debt service $D_{l f}(x)$ (debt amortization plus interest) as well as a tax payment $T_{l f}(x)$ are due. A corporate income tax $T_{\text {cit }}(x)$ and a shareholder level tax $T_{s}(x)$ sum up to the total tax burden $T_{c}(x):=T_{\mathrm{cit}}(x)+T_{s}(x)$ for corporations, while partnerships are treated as pass-through entities and taxed with personal income tax $T_{p}(x)$. Once all payments are made, the firm is liquidated.

The investors choose the organizational form such as to maximize their expected future value $E\left[F V_{l f}(x)\right]$, which results from the project's cash flows less debt service and tax payment,

$$
F V_{l f}(x):=x-D_{l f}(x)-T_{l f}(x) .
$$

Maximizing the expected future value is equivalent to maximizing the expected net present value, $E\left[N P V_{l f}(x)\right]:=\frac{E\left[F V_{l f}(x)\right]}{1+r_{f}\left(1-\tau_{i}\right)}-(1-\lambda) I_{0}$, where interest is taxable at rate $\tau_{i}$, since the invested equity $(1-\lambda) I_{0}$ is exogenous and the opportunity cost is, therefore, constant.

The cash flows' probability distribution $f(x)$ is independent of the legal form and $x$ may or may not suffice to cover the firm's liabilities. If the investors choose a partnership, we assume the potentially outstanding amount to be covered by sufficient collateral from private wealth. Liabilities are, therefore, always completely met and debt capital is available at the risk-free interest rate $r_{f}$. The partnership's payment to the creditors is independent of the project's uncertain return, $x$, and amounts to the constant $D_{p}:=\lambda\left(1+r_{f}\right)$.

If on the other hand the investors found a corporation, their liability is limited to the firm's wealth and the firm may default on debt payment if $x$ is small. The payment to the creditors is given by

$$
D_{c}(x):=\min \left\{\lambda(1+i) ; x-T_{\mathrm{cit}}(x)\right\} .
$$

Note that the default probability is not exogenously given by the probability distribution of $x$, but rather depends as well on the tax function $T_{\text {cit }}(x)$ and is 
interdependent with the debt interest rate $i$. We define $x_{0}$ as the critical cash flow that is necessary to satisfy the creditors after considering tax payments. The default probability is now given as $P\left(x<x_{0}\right)$, where $P$ is the probability measure. Note that in case of a taxable loss, the tax payment is negative and increases the payment to the creditors, as long as full loss offset is assumed.

We assume symmetric information, and the risk neutral creditors thus charge a risk premium $\rho>0$ to the risky interest rate $i:=r_{f}+\rho$ such that the expected debt payment equals the certain payment $\lambda\left(1+r_{f}\right)$. Note that $\rho$ is not a risk premium in the meaning of expected utility theory, but rather describes the difference between the nominal interest rate and risk-free interest rate. Due to the risk-neutrality of creditors, the expected interest rate always equals the risk-free interest rate. The interest rate is, therefore, endogenously determined by the condition

$$
E\left[D_{c}\right] \stackrel{!}{=} \lambda\left(1+r_{f}\right)=D_{p}
$$

The investors choose the organizational form that leads to the higher expected future value. The optimal choice is denoted as $l f^{*}$ :

$$
l f^{*}:= \begin{cases}c, & \text { if } E\left[F V_{c}(x)\right]>E\left[F V_{p}(x)\right], \\ p, & \text { if } E\left[F V_{c}(x)\right]<E\left[F V_{p}(x)\right] .\end{cases}
$$

Applying (1) and (3) easily shows that the investors' decision only depends on the expected tax payments $E\left[T_{c}(x)\right]$ and $E\left[T_{p}(x)\right]$ :

$$
\begin{aligned}
E\left[F V_{c}(x)\right] & >E\left[F V_{p}(x)\right] \\
\Leftrightarrow E[x]-E\left[D_{c}(x)\right]-E\left[T_{c}(x)\right] & >E[x]-D_{p}-E\left[T_{p}(x)\right] \\
\Leftrightarrow E\left[T_{c}(x)\right] & <E\left[T_{p}(x)\right] .
\end{aligned}
$$

The investors choose the legal form with the smaller expected tax burden. If $E\left[T_{c}(x)\right]=E\left[T_{p}(x)\right]$, risk neutral investors are indifferent between the legal forms and between limited and unlimited liability.

Exogenous parameters are the investment amount $I_{0}$, the leverage $\lambda$, the risk-free interest rate $r_{f}$ as well as the tax rates and the later introduced IDR parameters. Endogenous and certain are the risk-free debt service $D_{p}$, the later introduced critical cash flows $x_{\mathrm{DG}}, x_{2 p}, x_{2 l}$ and the dividend effect. All other variables including the risky interest rate are stochastic.

\subsection{Assumptions on taxation}

Regarding taxation, the following assumptions apply for the whole analysis:

- Full capitalization of the investment expenditure $I_{0}$ in $t=0$ and full depreciation in $t=1$.

- Proportional tax rates $\tau_{l f}$.

- Full and immediate loss offset. (This assumption is weakened in Sect. 4.)

- Debt capital is redeemed before interest is paid. 
Furthermore, we assume for the baseline model:

- Full deductibility of interest expenses.

- Full taxability of default gains.

A corporation defaults, if cash flows after tax do not suffice to cover debt redemption plus interest. Default gains arise when the corporation pays back less than the nominal debt amount $\lambda$ and not even partial interest, i.e., the case $D_{c}(x)-\lambda<0$. Note that default gains cannot be "distributed" to shareholders since claims of creditors are met first. Dividend payments require full debt redemption and interest payment. The economic "benefit" of default gains is that losses are partially borne by creditors instead of by the investors' equity. The default gain on corporate level mirrors the creditors' default loss.

The taxation of the creditors' interest income has no impact on the creditors' calculus in (3) and is, therefore, neglected. To see this, assume that interest income is taxed at rate $\tau_{i}$ and the creditors' expected net payment is thus $D_{p}^{\text {net }}=$ $\lambda\left(1+r_{f}\left(1-\tau_{i}\right)\right)$ in case of a partnership and $E\left[D_{c}^{\text {net }}\right]=\lambda+E\left[D_{c}-\lambda\right] \cdot\left(1-\tau_{i}\right)$ in case of a corporation. Now note that the term $\left(1-\tau_{i}\right)$ is cancelling out in $E\left[D_{c}^{\text {net }}\right] \stackrel{!}{=} D_{p}^{\text {net }}$, resulting in condition (3) from above.

\subsection{Expected tax payments}

A partnership's taxable income is the project's gross return less the depreciation of $I_{0}=1$ and less the certain interest payment to the creditors. With the personal income tax rate $\tau_{p}$, one obtains

$$
E\left[T_{p}(x)\right]=\tau_{p} E\left[x-1-\lambda r_{f}\right]=\tau_{p} E\left[x-1-\left(D_{p}-\lambda\right)\right] .
$$

Regarding a corporation, one has to additionally differentiate between corporate level and shareholder level taxation. Applying the corporate income tax rate $\tau_{\text {cit }}$, one obtains the corporate level tax payment as

$$
T_{\text {cit }}(x):=\tau_{\text {cit }}\left(x-1-\left(D_{c}(x)-\lambda\right)\right) .
$$

Due to the limitation of liability, there are three differences in the tax base on corporate level in comparison to the partnership's tax base: first, the demanded interest rate is higher than the partnership's interest payment (compensating the default risk) so that the actual interest payment may be greater. Second, the actual interest payment may be smaller in case of insufficient cash flows. Third, default gains $\mathrm{DG}:=\max \left\{\lambda-D_{c}(x) ; 0\right\}$ occur if the corporation's liquidity does not cover redemption of debt. Depending on the realization of $x$, the tax base is either reduced by the interest payment $D_{c}(x)-\lambda>0$, if $x-T_{\text {cit }}(x)>\lambda$, or increased by the default gains $D_{c}(x)-\lambda<0$, if $x-T_{\text {cit }}(x)<\lambda$.

Integrating the shareholder level taxation, $T_{s}(x)$, with tax rate $\tau_{s}$ and taking expectations results in the corporation's expected total tax burden, 


$$
E\left[T_{c}(x)\right]=E\left[T_{\text {cit }}(x)+T_{s}(x)\right]=\tau_{c} \cdot E\left[x-1-\left(D_{c}(x)-\lambda\right)\right],
$$

where $\tau_{c}=\tau_{\text {cit }}+\tau_{s} \cdot\left(1-\tau_{\text {cit }}\right)$. Using (3), the comparison of (6) and (8) shows that the expected tax burdens differ in the tax rates only. To analyze distortions in the choice of organizational form which are caused by variations in interest deductibility, we abstract from tax rate differences and set $\tau_{p}=\tau_{c}=: \tau$, so that the expected future values of partnership and corporation are equal within the baseline model. Accordingly, risk neutral investors are indifferent between the two organizational forms. Note that we do not aim at deriving tax planning recommendations for entrepreneurs. In this case, we would have to integrate all other tax differences between legal forms as is common in tax planning studies on the choice of organizational form using complete financial plans (e.g., König et al. 2013).

\section{Interest deductibility restrictions (IDR)}

In this section we analyze the effects of the two most common interest deductibility restrictions on the choice of organizational form. From the baseline model's neutral design it is clear that any preference for a partnership or a corporation must be caused by the analyzed interest deductibility restriction. After the expected tax burdens of both organizational forms do exactly match in the baseline model with full interest deductibility and full taxability of default gains, i.e., $E\left[T_{c}(x)\right]=E\left[T_{p}(x)\right]$, it is now sufficient to analyze the additional tax burden $E\left[\Delta T_{l f, \mathrm{IDR}}(x)\right]$ that is caused by the respective IDR. Investors prefer a partnership over a corporation if $E\left[\Delta T_{p, \mathrm{IDR}}(x)\right]<E\left[\Delta T_{c, \mathrm{IDR}}(x)\right]$ and vice versa. In case of $E\left[\Delta T_{p, \mathrm{IDR}}(x)\right]=E\left[\Delta T_{c, \mathrm{IDR}}(x)\right]$ they are indifferent. In the corporation case, IDR apply on corporate level only and shareholder level tax is only indirectly affected by the change in dividend payments. The expected total tax increase is $E\left[\Delta T_{c, \mathrm{IDR}}(x)\right]=\left(1-\tau_{s}\right) E\left[\Delta T_{\text {cit,IDR }}(x)\right]$.

To analyze an IDR, one has to specify the cases in which interest payments do and do not occur. While the partnership's interest payment is certain and does not depend on the project's return, the corporation's interest payment or default gain do depend on the realization of $x$. As long as $x<\lambda+T_{\text {cit }}(x)$, the corporation not only fails to pay any interest, but moreover realizes a default gain for paying back less than the nominal debt amount. For $x>\lambda+T_{\text {cit }}(x)$, debt capital is fully redeemed and interest paid at least partially. Full interest payment requires $x \geq \lambda(1+i)+T_{\text {cit }}(x)$. We define $x_{\mathrm{DG}}$ and $x_{0}$ as the critical gross returns that distinguish between the three cases, as is illustrated in Fig. 1.

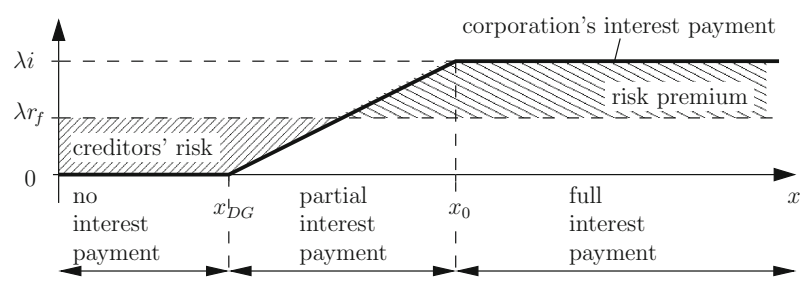

Fig. 1 Critical cash flows for a corporation 


\subsection{IDR based on leverage ratio}

\subsubsection{General model}

The most widespread class of IDR links the limitation of interest deductibility to the leverage ratio. Interest payments are deductible as far as a fixed leverage ratio $\alpha$, defined as debt-to-equity ratio, is not exceeded. Interest payment on excessive debt is non-deductible. Typical admissible debt-to-equity ratios reach from 1.5 to 1 (France, the United States, and until 2008 also Germany, equivalent to a debt-tototal assets ratio of $60 \%$ ) over 2 to 1 (Canada), 3 to 1 (Japan and New Zealand), and 4 to 1 (the Netherlands, Latvia and Lithuania) up to 6 to 1 (Luxembourg). For a broader overview of allowance limits refer to Webber (2010). For given equity $(1-\lambda)$, the admissible debt, the so-called "safe haven", is the product $\alpha(1-\lambda)$. For low leverage $\lambda \leq \frac{\alpha}{1+\alpha}$, the IDR is not binding, as $\lambda \leq \alpha(1-\lambda)$, i.e., the actual debt is below the admissible debt. The additional tax is zero and the baseline model applies. This holds for both corporations and partnerships. For leverage above that limit, the excessive debt is $\lambda-\alpha(1-\lambda)$ : total debt less admissible debt. Interest payments are non-deductible to the part that the total debt exceeds the admissible debt, i.e., the ratio of excessive and total debt. We define $\alpha^{\prime}$ as that ratio,

$$
\alpha^{\prime}:=\frac{\lambda-\alpha(1-\lambda)}{\lambda}=1-\frac{\alpha}{\Lambda},
$$

where $\Lambda:=\frac{\lambda}{1-\lambda}$ is the actual leverage ratio, and we name $\alpha^{\prime}$ the non-deduction factor. For total interest payments $D_{l f}(x)-\lambda>0$, the amount of non-deductible interest is $\alpha^{\prime}\left(D_{l f}(x)-\lambda\right)$. Hence, for given leverage, the restriction in interest deductibility can be expressed by a proportional factor $\alpha^{\prime}$ that is modulated by the choice of $\lambda$. While the admissible leverage ratio $\alpha$ may be any positive real number, the non-deduction factor $\alpha^{\prime}$ is $\in(0,1]$, if $\lambda>\frac{\alpha}{1+\alpha}$, and zero otherwise.

The partnership's interest payment is independent of the realization of $x$ and leads to a certain additional tax payment of

$$
E\left[\Delta T_{p 1}\right]=\tau_{p} \alpha^{\prime}\left(D_{p}-\lambda\right)=\tau_{p} \alpha^{\prime} \lambda r_{f} .
$$

By contrast, the corporation's interest payment depends on the realization of $x$, as outlined in Fig. 1. The corporation's additional tax payment is $\tau_{\mathrm{cit}} \alpha^{\prime}\left(D_{c 1}(x)-\lambda\right)$ when interest is paid, i.e., if $x>x_{\mathrm{DG}}$. Default gains are usually fully taxable and unaffected by leverage-based IDR and there is neither additional tax expense nor refund, when $x \leq x_{\mathrm{DG}}$. Alternatively, the legislator might consider the corresponding occurrence of default gains and set an equivalent proportional factor $\beta^{\prime}$ with $0 \leq \beta^{\prime} \leq 1$ to exempt default gains. German tax law before 1998, for example, applied $\beta^{\prime}=1$. If so, in comparison to the baseline model default gains lead to a negative additional tax of $\tau_{\text {cit }} \beta^{\prime}\left(D_{c 1}(x)-\lambda\right)$, where $D_{c 1}(x)-\lambda<0$. An increase in corporate level tax leads to an equally large decrease in dividend payment and a decrease in shareholder level tax, such that the expected total increase in tax burden including shareholder taxation is 


$$
E\left[\Delta T_{c 1}(x)\right]=\left(1-\tau_{s}\right) \tau_{\mathrm{cit}} \cdot E\left[\operatorname{IDR}_{1}(x)\right]
$$

where

$$
\operatorname{IDR}_{1}(x)= \begin{cases}\alpha^{\prime}\left(D_{c 1}(x)-\lambda\right), & \text { if } x>x_{\mathrm{DG}}, \\ \beta^{\prime}\left(D_{c 1}(x)-\lambda\right), & \text { if } x<x_{\mathrm{DG}}, \\ 0, & \text { if } x=x_{\mathrm{DG}}\end{cases}
$$

For $\alpha^{\prime}=0$, the actual debt does not exceed the admissible debt and interest expenses are fully deductible, and for $\beta^{\prime}=0$, default gains are fully taxable, as in the baseline model. Interest non-deductibility increases with $\alpha^{\prime}$ and default gain exemption with $\beta^{\prime}$. For $\alpha^{\prime}=1$ and $\beta^{\prime}=1$, interest expenses are fully non-deductible and default gains are fully tax-exempt. The non-deductible amount of interest expenses, $\alpha^{\prime} \cdot \max \left\{D_{l f}-\lambda ; 0\right\}$, leads to an increased tax payment, whereas the exempted amount of default gains, $\beta^{\prime} \cdot \min \left\{D_{l f}-\lambda ; 0\right\}$, leads to a reduced tax payment. For $\beta^{\prime}=\alpha^{\prime}$, default gains are tax-exempt to the same proportion that interest is nondeductible.

To simplify the comparison of $E\left[\Delta T_{p 1}\right]$ and $E\left[\Delta T_{c 1}\right]$ we solve $E\left[\operatorname{IDR}_{1}(x)\right]$ in (11), rearrange the result, use that $\left(1-\tau_{s}\right) \tau_{\mathrm{cit}}=\tau-\tau_{s}$ and obtain:

\section{Lemma 1}

$$
E\left[\Delta T_{c 1}(x)\right]=\underbrace{\tau \alpha^{\prime} \lambda r_{f}}_{\text {AT }}-\underbrace{\tau_{s} \alpha^{\prime} \lambda r_{f}}_{\text {div_effect }}+\underbrace{\left(1-\tau_{s}\right) \tau_{\text {cit }}\left(\beta^{\prime}-\alpha^{\prime}\right) \cdot \int_{0}^{x_{\mathrm{DG}}}\left(D_{c 1}(x)-\lambda\right) f(x) \mathrm{d} x}_{\text {DG_effect }} .
$$

where $f(x)$ is the cash flow distribution's probability density function.

All omitted proofs can be found in the "Appendix".

The first term, AT, represents the additional tax burden when a symmetric default gain exemption is assumed, i.e., $\alpha^{\prime}=\beta^{\prime}$, and when dividend taxation is neglected. AT is constant and matches the partnership's additional tax. For any positive shareholder tax rate $\tau_{s}>0$, the second term is nonzero and countervails the additional tax burden with a negative 'tax factor' $\tau_{s}$. We call this the dividend effect. For any $\beta^{\prime} \neq \alpha^{\prime}$, i.e., asymmetric treatment of default gains, the third term becomes nonzero, which expresses the change in total tax burden caused by the asymmetric treatment. The effect's sign depends on the relation of $\alpha^{\prime}$ and $\beta^{\prime}$.

To further analyze the effects on the choice of organizational form, we now compare Eqs. (10) and (13) for varying parameters. We consider different corporate tax systems as well as variations in the taxation of interest payments and default gains. The investors are indifferent if and only if the default gain effect and the dividend effect are of equal value,

$$
E\left[\Delta T_{c 1}(x)\right]=E\left[\Delta T_{p 1}(x)\right] \Leftrightarrow \mathrm{DG} \_ \text {effect }=\text { div_effect. }
$$




\subsubsection{Symmetric treatment of interest and default gains}

We first consider symmetric treatment of interest and default gains $\left(0<\alpha^{\prime}=\beta^{\prime} \leq 1\right)$ in a tax system where dividends are tax-exempt $\left(\tau_{s}=0\right)$. Second, we consider a tax system where dividends are taxed at a rate $\tau_{s}>0$.

Within our model framework, the following propositions hold:

Proposition 1 In a tax system with symmetric treatment of interest payments and default gains and without shareholder level taxation, investors are indifferent between a partnership and a corporation.

Proof For $\tau_{s}=0$, the dividend effect is zero and due to $\alpha^{\prime}=\beta^{\prime}$, the DG effect is zero, too. The remaining additional tax AT equals the partnership's expected additional tax burden, thus

$$
\begin{aligned}
E\left[\Delta T_{c 1}(x)\right] & =\mathrm{AT}-\text { div_effect }+\mathrm{DG} \_ \text {effect } \\
& =\tau \alpha^{\prime} \lambda r_{f}-0+0=E\left[\Delta T_{p 1}(x)\right] .
\end{aligned}
$$

The considered tax system is neutral in the sense that the choice of organizational form is not distorted by the IDR.

Note that the depicted equality holds for the expected values only. For any given $x$, the actual tax payments do generally differ between the two forms.

The intuition for the organization form neutrality is as follows: The tax exemption of default gains works as a compensation for the interest deductibility restrictions. If interest and default gains are treated symmetrically for tax purposes, this ensures that the expected payments to the creditors are (partly) tax deductible. As the expected payments to the creditors do not depend on the legal form in our model, the effect of the IDR is the same for corporations and partnerships as long as no other tax difference (e.g., dividend tax) exists.

Proposition 2 In a tax system with symmetric treatment of interest and default gains and with shareholder level taxation, investors choose a corporation.

Proof The default gain effect remains zero, whereas the dividend effect now becomes positive:

$$
\begin{aligned}
E\left[\Delta T_{c 1}(x)\right] & =\mathrm{AT}-\mathrm{div} \_ \text {effect }+\mathrm{DG} \_ \text {effect } \\
& =\tau \alpha^{\prime} \lambda r_{f}-\tau_{s} \alpha^{\prime} \lambda r_{f}+0<\tau \alpha^{\prime} \lambda r_{f}=E\left[\Delta T_{p 1}(x)\right] .
\end{aligned}
$$

The expected additional tax burden is smaller for corporations than for partnerships.

Integrating dividend taxation into a former neutral tax system with symmetric treatment of interest and default gains distorts the choice of organizational form. The allocation of the tax burden onto corporate level and shareholder level causes an advantage for the corporation that can, however, be compensated by adjusting the IDR's parameters. To ensure neutrality of the tax system, the IDR's design has to account for the organizational form. The partnership's disadvantage due to the higher tax rate on firm level must be compensated by a lower restriction factor. 
Within our model framework, the following proposition holds:

Proposition 3 In a tax system with symmetric treatment of interest and default gains and with shareholder level taxation, there exist specific $\alpha_{p}^{\prime} \neq \alpha_{c}^{\prime}$ for partnerships and corporations such that investors are indifferent between a partnership and a corporation.

Proof

$$
E\left[\Delta T_{c 1}\right]=E\left[\Delta T_{p 1}\right] \Leftrightarrow\left(\tau-\tau_{s}\right) \alpha_{c}^{\prime} \lambda r_{f}=\tau \alpha_{p}^{\prime} \lambda r_{f} \Leftrightarrow \alpha_{p}^{\prime}=\alpha_{c}^{\prime}\left(1-\frac{\tau_{s}}{\tau}\right) .
$$

A neutral tax system requires either $\alpha_{p}^{\prime}=\alpha_{c}^{\prime}=0$ (no interest deductibility restriction) or $\tau_{s}=0$ or $\alpha_{p}^{\prime}<\alpha_{c}^{\prime}$ with the relation in Eq. (17).

\subsubsection{Asymmetric treatment of interest and default gains}

We now consider asymmetric treatment of interest and default gains, $\alpha^{\prime} \neq \beta^{\prime} \in[0,1]$, first in a tax system where dividends are tax-exempt $\left(\tau_{s}=0\right)$, and subsequently in a tax system where dividends are taxed at a rate $\tau_{s}>0$.

Within our model framework, the following propositions hold:

Proposition 4 In a tax system with asymmetric treatment of interest and default gains and without shareholder taxation, investors choose a corporation if $\alpha^{\prime}<\beta^{\prime}$ and a partnership if $\alpha^{\prime}>\beta^{\prime}$.

Proof As in Proposition 1, no dividend effect occurs and the corporation's tax burden exceeds the partnership's if the DG effect is positive. We obtain

$$
\text { DG_effect }=\left(\beta^{\prime}-\alpha^{\prime}\right)\left(1-\tau_{s}\right) \cdot \tau_{\text {cit }} \int_{0}^{x_{\mathrm{DG}}}(\overbrace{D_{c 1}(x)-\lambda}^{<0} f(x) \mathrm{d} x,>0 \Leftrightarrow \alpha^{\prime}>\beta^{\prime},
$$

because $D_{c 1}(x)-\lambda<0 \forall x<x_{\text {DG }}$. For $\alpha^{\prime}>\beta^{\prime}$, the DG effect is positive and the corporation's tax burden exceeds the partnership's. Vice versa for $\alpha^{\prime}<\beta^{\prime}$.

The DG effect is a measure for discrimination. If it is positive (negative), corporations are ceteris paribus relatively discriminated against (privileged). Discrimination of an organizational form thus depends on the taxable treatment of default gains.

Proposition 5 In a tax system with asymmetric treatment of interest and default gains and with shareholder level taxation, investors choose a corporation if $\alpha^{\prime}<\beta^{\prime}$. For $\alpha^{\prime}>\beta^{\prime}$, the investors' choice depends on the cash flows' distribution assumption.

Proof Both effects are nonzero and we have 


$$
\begin{aligned}
E\left[\Delta T_{c 1}(x)\right]<E\left[\Delta T_{p 1}(x)\right] & \Leftrightarrow \tau \alpha^{\prime} \lambda r_{f}-\text { div_effect }+ \text { DG_effect }<\tau \alpha^{\prime} \lambda r_{f} \\
& \Leftrightarrow \text { DG_effect }<\text { div_effect. }
\end{aligned}
$$

The dividend effect is positive and always privileges the corporation. The sign of the default gain effect is parameter dependent. For $\alpha^{\prime}<\beta^{\prime}$, it adds on top of the dividend effect and makes the corporation even more privileged. In the opposite case $\alpha^{\prime}>\beta^{\prime}$, the DG effect has positive sign and counteracts the dividend effect:

$$
\text { DG_effect }<\text { div_effect } \Leftrightarrow\left(\beta^{\prime}-\alpha^{\prime}\right)\left(1-\tau_{s}\right) \tau_{\text {cit }} \cdot \underbrace{\int_{0}^{x_{\mathrm{DG}}}\left(D_{c 1}(x)-\lambda\right) f(x) \mathrm{d} x}_{<0}<\tau_{s} \alpha^{\prime} \lambda r_{f} .
$$

The total effect privileges the corporation if $\alpha^{\prime}<\beta^{\prime}$, and in the opposite case depends on the absolute values of both effects, which of the default gain effect in turn depends on the probability distribution of $x$. Without a distribution assumption, the total effect is undetermined.

Proposition 6 For $\alpha^{\prime} \neq \beta^{\prime}, \tau_{s} \geq 0$ and $0<\tau_{\text {cit }}<1$, there exist in general neither specific $\alpha_{p}^{\prime}, \alpha_{c}^{\prime}$, nor other parameter modifications such that the investors are indifferent regarding the legal form.

Proof A tax regime that is neutral to the choice of legal form for any possible distribution assumption requires that one form's expected tax burden does not depend on the cash flow distribution if the other's does not either. From (10) we know that the partnership's expected tax burden is constant, i.e., does not depend on the distribution of $x$. We have just seen that the dividend effect is constant, too, but the default gain effect in general is not. We now further analyze the default gain effect and show that no parameter tweaks can change this result. Given this, the tax system cannot be neutral.

The default gain effect in (13) is the product of a tax factor and the default gain expectancy,

$$
\begin{aligned}
& \text { DG_effect }=\left(1-\tau_{s}\right) \tau_{\mathrm{cit}}\left(\beta^{\prime}-\alpha^{\prime}\right) \cdot \mathrm{EDG}, \\
& \text { where EDG }:=\int_{0}^{x_{\mathrm{DG}}}\left(D_{c 1}(x)-\lambda\right) f(x) \mathrm{d} x .
\end{aligned}
$$

Lemma 2 Solving Eq. (22) yields $x_{\mathrm{DG}}=\lambda-\frac{\tau_{\mathrm{cit}}}{1-\tau_{\mathrm{cit}}} \cdot(1-\lambda)$ and

DG_effect $=\left(\alpha^{\prime}-\beta^{\prime}\right)\left(1-\tau_{s}\right) \tau_{\mathrm{cit}} \frac{1-\tau_{\mathrm{cit}}}{1-\tau_{\mathrm{cit}}\left(1-\beta^{\prime}\right)} \cdot E\left[x_{\mathrm{DG}}-x \mid x<x_{\mathrm{DG}}\right] \cdot P\left(x<x_{\mathrm{DG}}\right)$. 
The default gain effect is the product of a tax factor, the expected shortfall in cash flows in case of $x<x_{\mathrm{DG}}$ and the probability of $x<x_{\mathrm{DG}}$. The legislator can specify the tax factor, but obviously not the distribution dependent factors. The tax factor is zero if and only if $\tau_{\text {cit }}=0$ (no corporate level taxation), $\tau_{\text {cit }}=1$ (100\% taxation on corporate level), $\tau_{s}=1$ (100\% taxation on shareholder level) or $\alpha^{\prime}=\beta^{\prime}$ (symmetric treatment of interest payments and default gains). For any other parameters, the tax factor is nonzero and the DG effect is distribution dependent.

\subsection{IDR based on EBITDA}

Instead of defining a maximum admissible debt ratio, some tax jurisdictions limit the fraction of net earnings to be admissibly spent on interest. We consider an IDR that permits interest deduction up to the fraction $\gamma>0$ of earnings before interest, taxes, depreciation and amortization (EBITDA). Exceeding interest payments are non-deductible. Typical values for $\gamma$ are $30 \%$ (Germany since 2008 and Italy) and $50 \%$ (United States, applied as an additional condition after the debt-to-equity test). In line with our baseline model, we assume full depreciation of the investment expenditure at $t=1$ with the result that the EBITDA equals the cash flows $x$. The maximum amount of deductible interest expenses is thus $\gamma x$ and the non-deductible interest amounts to $\max \left\{D_{l f, 2}(x)-\lambda-\gamma x ; 0\right\}$. Hence, the effectiveness of this IDR and, therefore, the additional tax burden, too, depend on the realization of $x$ : as $x$ increases, the admissible amount of deductible interest increases. Note that in contrast to Sect. 3.1, the parameter $\gamma$ denotes the deductible fraction of the EBITDA.

Within our model framework, the following proposition holds:

Proposition 7 In a tax system where interest deductibility is restricted to a fraction $\gamma$ of EBITDA, the investors' choice of organizational form depends on the cash flows' distribution.

Proof While the partnership's interest payment $\lambda r_{f}$ is certain, the deduction limit $\gamma x$ is not. We define $x_{2 p}$ as the critical cash flow that just allows the partnership to deduct the whole interest, i.e., $x_{2 p}:=\frac{\lambda r_{f}}{\gamma}$. For $x \geq x_{2 p}\left(x<x_{2 p}\right)$, interest expenses do not exceed (do exceed) the admissible amount $\gamma x$. For $x=0$, the admissible amount is zero and interest expenses are fully non-deductible.

Hence, the partnership's additional tax depends on the realization of $x$ :

$$
\Delta T_{p 2}(x)=\tau_{p} \cdot\left\{\begin{array}{cc}
\lambda r_{f}-\gamma x, & \text { if } x<x_{2 p}, \\
0, & \text { else }
\end{array}\right.
$$

The expectation is

$$
E\left[\Delta T_{p 2}\right]=\tau_{p}\left(\lambda r_{f}-\gamma E\left[x \mid x<x_{2 p}\right]\right) \cdot P\left(x<x_{2 p}\right) .
$$

The IDR is effective for the partnership, if $P\left(x<x_{2 p}\right)$ is positive, i.e., if chances are that cash flows can fall below the threshold of $x_{2 p}$, which depends on the distribution assumption. A positive probability for $x=0$ is usually assumed. 


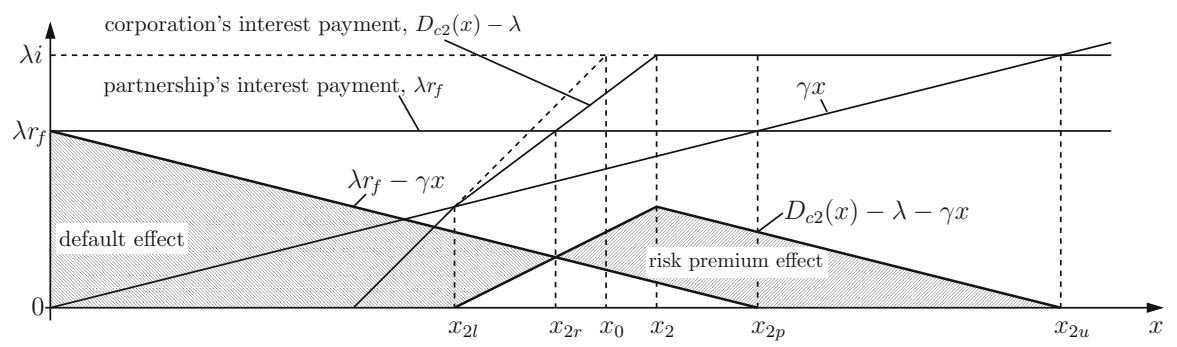

Fig. 2 Effects of an EBITDA-based IDR

The case is more complex for the corporation: not only does the allowance limit, $\gamma x$, increase with $x$, but the interest payment, $D_{c 2}(x)-\lambda$, does, too, until it approaches the due amount $\lambda i$ at $x=x_{2}$, as depicted in Fig. 2. If the allowance parameter $\gamma$ is sufficiently large, the IDR may not be binding for the corporation at all. If so, investors choose a corporation, should the IDR be binding for the partnership, and they are indifferent if the IDR is effective for neither legal form.

If the IDR is instead effective for the corporation for some $x$, one must determine the condition on $x$ for the effectiveness. We define $x_{2}$ as the minimum cash flow that allows full debt service, i.e., $x_{2}:=\inf \left\{x \mid D_{c 2}(x)=\lambda(1+i)\right\}$. The excess interest, $D_{c 2}(x)-\lambda-\gamma x$, reaches its maximum at $x_{2}$, because the actual interest remains constant from there on as the allowance limit further rises. It eventually becomes zero at $x_{2 u}:=\inf \left\{x \mid D_{c 2}(x)-\lambda-\gamma x=0, x>x_{2}\right\}$, which is an upper bound for the effectiveness of this IDR, similar to $x_{2 p}$ for the partnership. In case of default $\left(x<x_{2}\right)$, there are three sub cases: no interest payment occurs if $D_{c 2}(x)-\lambda \leq 0$, thus, the restriction in interest deductibility cannot lead to an additional tax payment. For $0<D_{c 2}(x)-\lambda<\lambda i$, interest liabilities are partly paid, but the IDR causes an increase in the tax base only if also $D_{c 2}(x)-\lambda-\gamma x>0$. We define $x_{2 l}:=\inf \left\{x \mid D_{c 2}(x)-\lambda-\gamma x \geq 0\right\}$, which is the lower bound for the IDR's effectiveness.

The tax burden on corporate level with respect to the interest deductibility restriction is now

$$
T_{\text {cit } 2}(x)=\tau_{\text {cit }}\left(x-1-\left(D_{c 2}(x)-\lambda\right)\right)+\tau_{\text {cit }} \cdot \operatorname{IDR}_{2}(x),
$$

where

$$
\operatorname{IDR}_{2}(x)= \begin{cases}D_{c 2}(x)-\lambda-\gamma x, & \text { if } x \in\left(x_{2 l}, x_{2 u}\right), \\ 0, & \text { else, }\end{cases}
$$

and taking expectations yields

$$
E\left[T_{\mathrm{cit} 2}(x)\right]=\underbrace{\tau_{\mathrm{cit}} E[x]-\tau_{\mathrm{cit}}\left(1+\lambda r_{f}\right)}_{=E\left[T_{\mathrm{cit}}(x)\right]}+\tau_{\mathrm{cit}} \cdot E\left[\operatorname{IDR}_{2}(x)\right] .
$$

Using this, the expected change in corporate level tax is $E\left[\Delta T_{\text {cit } 2}(x)\right]:=$ $E\left[T_{\text {cit } 2}(x)\right]-E\left[T_{\text {cit }}(x)\right]=\tau_{\text {cit }} E\left[\operatorname{IDR}_{2}(x)\right]$ and considering shareholder level taxation on the hereby reduced dividend payout yields the total expected additional tax, 


$$
E\left[\Delta T_{c 2}(x)\right]=\left(1-\tau_{s}\right) \tau_{\mathrm{cit}} E\left[\operatorname{IDR}_{2}(\mathrm{x})\right]
$$

Lemma 3 Solving $T_{\text {cit2 }}(x)$ and $\operatorname{IDR}_{2}(x)$ yields

$$
E\left[\Delta T_{c 2}(x)\right]=\left(1-\tau_{s}\right) \tau_{\mathrm{cit}}\left[\left(1-\tau_{\mathrm{cit}}\right)(1-\gamma) \int_{x_{2 l}}^{x_{2}}\left(x-x_{2 l}\right) f(x) \mathrm{d} x+\int_{x_{2}}^{x_{2 u}}(\lambda i-\gamma x) f(x) \mathrm{d} x\right] .
$$

The impact on the advantageousness of a legal form is ambiguous. Without further knowledge on the cash flows' probability distribution, it is undetermined if $E\left[\Delta T_{c 2}\right]>E\left[\Delta T_{p 2}\right]$ or vice versa.

To further explain the occurring effects, we use $x_{2 p}$ from above and $x_{2 r}:=$ $\inf \left\{x \mid D_{c 2}(x)-\lambda \geq \lambda r_{f}\right\}$ that distinguishes between the cases where the corporation's interest payment is greater or smaller than the partnership's. If $x_{2 r}<x<x_{2 u}$, the corporation's additional tax payment exceeds the partnership's due to the higher interest payment, as illustrated in Fig. 2. This risk premium effect discriminates against the corporation. If $x<x_{2 r}$, the corporation's additional tax payment falls below the partnership's, and it is even zero for $x<x_{2 l}$. This default effect, which privileges the corporation, is driven by the fact that the partnership is mostly hit by the IDR when cash flows are below the default threshold and the investors have to stand in for the interest payment. The magnitude of both effects and, therefore, the total impact of the IDR on the choice of organizational form depends on the distribution of the gross return $x$.

\section{IDR in the presence of a loss offset restriction (LOR)}

The so far applied model assumes a full and immediate loss offset, resulting in a negative tax base when cash flows are small. While the actual due tax amount cannot be negative in most jurisdiction, taxable losses can usually be offset against income from other sources and future profits. Full loss offset may, therefore, be a realistic assumptions for sole proprietorships and partnerships. Opposed to that, a defaulting corporation can make use of its taxable losses usually only in instances where the sole corporate body is re-used in another business, such as in shell company acquisitions. This is where loss offset restrictions (LOR) apply in many tax jurisdictions. This section assumes that shareholders and partnerships can, but corporations cannot offset taxable losses. This extends the presented model with a loss offset restriction rule that averts a negative assessment basis on corporate level such that $T_{\text {cit* }}(x) \geq 0 \forall x$. Variables and functions in this section are marked with the subscript " $*$ " to denote that a loss offset restriction applies. 


\subsection{Adjusted baseline model}

In this section, we present an adjusted baseline model with no IDR in effect, but with a loss offset restriction on corporate level. Interest is fully deductible and default gains are fully taxable. The corporate income tax function now reads

$$
\begin{aligned}
T_{\text {cit } *}(x) & =\max \left\{0, \tau_{\text {cit }}\left(x-1-\left(D_{c *}(x)-\lambda\right)\right)\right\} \\
& =: \tau_{\text {cit }}\left(x-1-\left(D_{c *}(x)-\lambda\right)\right)+\tau_{\text {cit }} \cdot \operatorname{LOR}_{*}(x),
\end{aligned}
$$

where

$$
\operatorname{LOR}_{*}(x)=: \begin{cases}0, & \text { if } x \geq 1+\lambda i \\ -\left(x-1-\left(D_{c *}(x)-\lambda\right)\right), & \text { if } x<1+\lambda i\end{cases}
$$

The expected corporate income tax is thus

$$
E\left[T_{\mathrm{cit} *}(x)\right]=\underbrace{\tau_{\mathrm{cit}} E\left[x-1-\left(D_{c *}(x)-\lambda\right)\right]}_{=E\left[T_{\mathrm{cit}}(x)\right]}+\tau_{\mathrm{cit}} E\left[\operatorname{LOR}_{*}(x)\right] .
$$

Comparing (33) with (7), one finds that the introduction of the LOR causes a rise in tax amounting to $\tau_{\text {cit }} E\left[\operatorname{LOR}_{*}(x)\right]$ : As the creditors' calculus (3) requires $E\left[D_{c *}(x)\right]=E\left[D_{c}\right]$, the first term in (33) equals the baseline model's expected corporate level tax. Since the rise in corporate tax translates into a decline in dividend payout and, therefore, in dividend tax, we observe a change in expected total tax in comparison to the baseline model of

$$
\begin{aligned}
E\left[\Delta T_{c *}(x)\right] & =\left(1-\tau_{s}\right)\left(E\left[T_{\mathrm{cit} *}(x)\right]-E\left[T_{\mathrm{cit}}(x)\right]\right) \\
& =\left(1-\tau_{s}\right) \tau_{\mathrm{cit}} E\left[\operatorname{LOR}_{*}(x)\right]=: \text { LOR_effect. }
\end{aligned}
$$

The LOR effect is positive and naturally discriminates against corporations, while the very amount depends on the distribution of cash flows:

$$
E\left[\operatorname{LOR}_{*}(x)\right]=\int_{0}^{\lambda(1+\mathrm{i})} \underbrace{(1-\lambda)}_{\geq 0} f(x) \mathrm{d} x+\int_{\lambda(1+i)}^{1+\lambda i} \underbrace{(1+\lambda i-x)}_{\geq 0} f(x) \mathrm{d} x \geq 0 .
$$

Figure 3 illustrates the two integrals in $\tau_{\text {cit }} E\left[\operatorname{LOR}_{*}(x)\right]$ as areas between the abscissa and the nominal corporate income tax function.

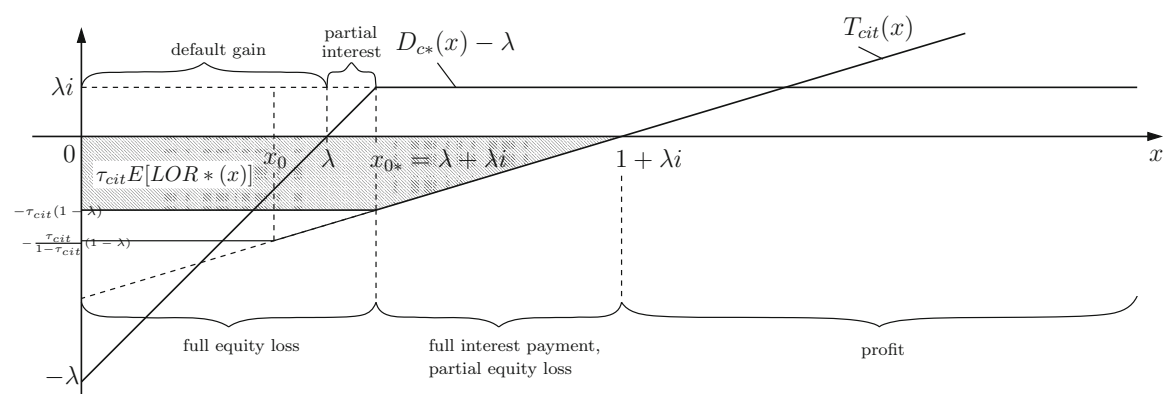

Fig. 3 Effect of a loss offset restriction 
Interaction between loss offset and interest deductibility restrictions is analyzed in the following.

\subsection{Introduction of IDR}

A leverage-based IDR-restricting interest deduction to the fraction $\alpha^{\prime}$ of total interest, as discussed in Sect. 3.1— can be expressed by means of a tariff function for corporate income tax

$$
t_{1 *}(x)=\tau_{\mathrm{cit}} \begin{cases}x-1-\left(1-\alpha^{\prime}\right)\left(D_{c 1 *}(x)-\lambda\right), & x \geq \lambda, \\ x-1-\left(1-\beta^{\prime}\right)\left(D_{c 1 *}(x)-\lambda\right), & x \leq \lambda,\end{cases}
$$

and analogously for an EBITDA-based IDR, restricting deduction to the fraction $\gamma$ of EBITDA,

$$
t_{2 *}(x)=\tau_{\text {cit }} \begin{cases}x-1-\gamma x, & x \in\left(x_{2 l *}, x_{2 u *}\right), \\ x-1-\left(D_{c 2 *}(x)-\lambda\right), & \text { else. }\end{cases}
$$

Combining this with a loss offset restriction, the corporate income tax function reads

$$
T_{\mathrm{cit}, \mathrm{IDR} *}(x)=\max \left\{0, t_{\mathrm{IDR} *}(x)\right\}=: \begin{cases}0, & x \leq x_{\mathrm{IDR}, t *}, \\ t_{\mathrm{IDR} *}(x), & x \geq x_{\mathrm{IDR}, t *}\end{cases}
$$

where IDR $\in\{1,2\}$ denotes which of the two IDR applies and $x_{\mathrm{IDR}, t *}:=$ $\inf \left\{x \geq 0 \mid t_{\mathrm{IDR} *}(x)>0\right\}$ is the critical cash flow for the tariff function to become positive. The LOR is binding for all $x<x_{\mathrm{IDR}, t *}$.

Lemma 4 The expected change in total tax caused by the introduction of a leverage-based IDR on top of an LOR_in comparison to the adjusted baseline model-equals

$$
E\left[\Delta T_{c 1 *}(x)\right]-\text { LOR_effect }=A T-\text { div_effect }+ \text { DG_effect }+ \text { interaction_effect }
$$

where both $A T=\tau \alpha^{\prime} \lambda r_{f}$ and div_effect $=\tau_{s} \alpha^{\prime} \lambda r_{f}$ are identical with those in Lemma 1,

$$
\text { DG_effect }=-\alpha^{\prime}\left(\tau-\tau_{s}\right) \int_{0}^{\lambda}\left(D_{c 1 *}(x)-\lambda\right) f(x) \mathrm{d} x
$$

is a default gain effect as in Lemma 1 with parameter setting $\beta^{\prime}=0$, and interaction_effect $<0$ is distribution dependent.

As in the model with full loss offset in Sect. 3.1, AT is the additional tax caused by the leverage-based IDR when legal form specific effects are neglected, and the dividend effect reduces a corporation's tax burden as compared to a partnership. 


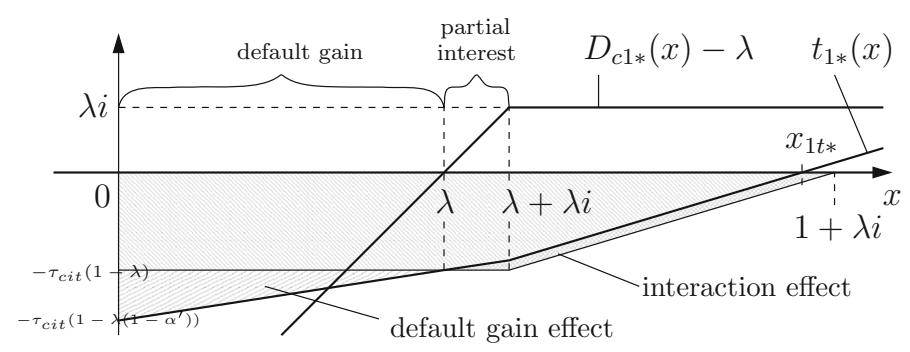

Fig. 4 LOR combined with leverage-based IDR

In combination of the LOR with the leverage-based IDR, an interaction effect results: in loss scenarios where the tax base is already negative, the IDR would only reduce tax refunds which are already excluded by the LOR. This effect is pro corporation because it renders the IDR partially ineffective for corporations. Thus, the disadvantage of the corporation compared to the partnership decreases. Furthermore, a symmetric treatment of interest and default gains that partially exempts default gains from taxation is no longer possible in the presence of an LOR (DG effect is always present). This is because an exemption would only add to an existing tax refund, which again is excluded by the LOR. This effect is contra corporation. Another contra corporation effect is that the excluded tax refunds in loss scenarios increase the expected default gain and thus the default gain effect. Creditors have to be compensated by paying a higher risk premium, to keep the expected creditors' return constant.

Proposition 8 In a tax system with a loss offset restriction on corporate level, the introduction of a leverage-based IDR has an arbitrary effect on the investors' choice of legal form depending on the cash flows' distribution assumption.

Proof It is analytically undetermined which of the counteracting and distribution dependent effects (dividend and interaction effects vs. default gain effect) stands out. The higher the probability that $x \in[\lambda, 1+\lambda i]$, the more does the interaction effect reduce the LOR effect, pronouncing the corporation's privilege from the dividend effect. Contrary to that, if $P(x<\lambda)$ is sufficiently large, the default gain effect may overcompensate the dividend and interaction effects and turn the privileging into a discrimination of corporations.

Figure 4 illustrates the LOR tax as the area between the tariff function $t_{1 *}(x)$ and the abscissa.

The implication of Proposition 8 is that a leverage-based IDR cannot be neutral to the choice of legal form if an LOR on corporate level is present.

Next consider an EBITDA-based IDR:

Lemma 5 An EBITDA-based IDR is effective for a corporation with LOR if and only if $\frac{\gamma}{1-\gamma}<\lambda i$. 
In a setting with an LOR, an EBITDA-based IDR is thus mostly ineffective, unless the $\gamma$ parameter is utterly small or the firm is highly leveraged. Introducing the IDR in a tax system where only corporations are subject to an LOR, therefore, adds a stronger burden on partnerships than on corporations. The following analysis assumes $\frac{\gamma}{1-\gamma}<\lambda i$.

Lemma 6 If $\gamma>i$, an EBITDA-based IDR is ineffective in default scenarios, because $x_{2 t *}>x_{2 *}$.

Lemma 7 If an EBITDA-based IDR is effective for a corporation and if $\gamma>i$, the increase in expected total tax burden caused by the introduction of the IDR on top of an existing LOR equals

$$
E\left[\Delta T_{c 2 *}(x)-\Delta T_{c *}(x)\right]=\left(1-\tau_{s}\right) \tau_{\mathrm{cit}}[\int_{x_{2 * *}}^{1+\lambda i} \underbrace{(x(1-\gamma)-1)}_{\geq 0} f(x) \mathrm{d} x+\int_{1+\lambda i}^{x_{2 u *}} \underbrace{(\lambda i-\gamma x)}_{\geq 0} f(x) \mathrm{d} x] .
$$

Proposition 9 In a tax system with a loss offset restriction on corporate level, the introduction of an IDR that limits deduction of interest to the fraction $\gamma$ of EBITDA has an arbitrary effect on the investors' choice of legal form depending on the cash flows' distribution assumption, if the IDR is binding for a corporation and if the deduction parameter $\gamma$ exceeds the risky interest rate $i$.

Proof Given these conditions, Lemmata 6 and 7 hold. Comparing (41) and (25) shows easily that the increase in total tax burden that is caused by the introduction of the IDR may be larger or smaller for any legal form, depending on the distribution assumption.

\section{Numerical illustrations}

Sections 3 and 4 show that there are a number of cases where the outcomes depend on the assumed probability distribution of cash flows. The aim of this section is to illustrate the analytically found effects for reasonable parameter settings and distribution assumptions using German tax facts and gross return data from German firms as an example.

\subsection{Setup}

Tax parameters Following German tax law, we assume a corporate tax system with shareholder relief, where a corporate income tax rate of $\tau_{\text {cit }}:=30 \%$ is imposed on corporate level and a dividend tax of $\tau_{s}:=25 \%$ on shareholder level, which results in a total tax burden of $\tau_{c}:=\tau_{\text {cit }}+\tau_{s}\left(1-\tau_{\text {cit }}\right)=47.5 \%$. Partnerships are treated as pass-through entities and pay a personal income tax rate $\tau_{p}$. We set $\tau_{p}=\tau_{c}=: \tau$ so as to achieve neutrality in the baseline model. 
Interest deductibility restrictions The IDR with a leverage-based restriction exhibits distribution dependent effects in the case of $\tau_{s}>0$ (positive dividend taxation) and $\alpha^{\prime}>\beta^{\prime}$ (asymmetric treatment of default gains). We now focus on this case and set $\beta^{\prime}=0$ (default gains are fully taxable) and $\alpha=1.5$, which allows for a debt-to-equity ratio of 1.5 to 1 , equivalent to a debt-to-total assets ratio of $60 \%$, and excludes interest expenses on exceeding debt from deduction. This is a typical allowance limit applied by a number of tax jurisdictions including France, the United States, and until 2008 also Germany. Other countries implemented the same rule with different debt-to-equity ratio limits, among them Canada (2 to 1), Japan and New Zealand (3 to 1), the Netherlands, Latvia and Lithuania (4 to 1) as well as Luxembourg (6 to 1). For a broader overview of allowance limits refer to Webber (2010).

The IDR's impact on the choice of legal form splits up into two components, a dividend effect and a default gain effect. From the theoretical analysis we know that in the considered scenario $\left(\tau_{s}>0, \alpha^{\prime}>\beta^{\prime}\right)$, the default gain effect puts a higher burden on corporations, whereas the dividend effect always gives an advantage to corporations over partnerships. The choice of legal form depends on which effect stands out. The allowance parameter $\alpha$ determines the total effect's magnitude, but not the direction. If an IDR turns out to discriminate against one legal form, a higher $\alpha$ results in a lower $\alpha^{\prime}$ and less discrimination, but cannot result in an advantage for the very legal form. We keep $\alpha$ constant and vary $\lambda$ between 0 and 1 to analyze which of the two effects usually stands out and which legal form is advantaged when realistic parameters are assumed.

The second common interest disallowance rule is one that limits the net interest expenses to a fraction $\gamma$ of EBITDA. Typical values for $\gamma$ are $30 \%$ (Germany since 2008, Italy) and $50 \%$ (United States, applied as an additional condition after the debt-to-equity test). In line with the current German law, we use a parameter value of $\gamma=30 \%$.

Interest rates Debt capital for a partnership with unlimited liability is available at the risk-free interest rate $r_{f}$. Empirical rates are taken from default-free zero coupon bonds with term to maturity of ten years, as estimated by Deutsche Bundesbank for the debt securities market (Listed Federal securities, Svensson method). The ten year term is an estimate for an average loan period. We use 2012's average daily value of $1.686 \%$ for the risk-free interest rate $r_{f}$. To test robustness, we present sensitivity analyses with varying $r_{f}$.

The risk premium for a corporation with limited liability is endogenously determined by the condition $E\left[D_{c}(x)\right]=\lambda\left(1+r_{f}\right)$. This is one of the main contributions from the simulation: while there is no analytical solution to the endogenous interest rate, a numerical approximation is readily available at high precision. The lack of an analytical solution is caused by the fact that the relevant probability distributions, such as the normal distribution or Levy alpha-stable distributions have no closed form solutions for the cumulative distribution functions. Note that the probability of default is, too, endogenously determined by the interest rate, a connection that is often ignored. 
Distribution assumption The firm's project requires a one-time investment of $I_{0}:=1$ at time $t=0$ and results in an uncertain gross return of $x \cdot I_{0}$ at time $t=1$. Empirical data is needed to calibrate the probability distribution of $x$. The challenge in adjusting the theoretical one-period model to a real world scenario is to fit empirical observations into the model's distribution assumption of gross return earned by the modeled company. Real world data from going concern businesses can at most give an estimate. This restriction applies to empirical distribution data as much as to any theoretical distribution with empirically adjusted parameters. Note that we only use empirical data to obtain a reasonable distribution of cash flows.

The variable $x$ denotes a company's life time period's cash flows, normalized to the initial investment expenditure $I_{0}$ that is required to generate the very amount of cash flows. Since the model assumes the company's liquidation at the end of the investment horizon as well as full capitalization and depreciation of the investment expenditure, the gross return $x$ is indeed identical to the amount of cash flows over the firm's life time. Opposed to that, empirical data reflect a single period in the life time of a going concern business. We assume that the randomly picked period is a representative fraction of the companies' life times. We approximate the invested capital $I_{0}$ by the average of the stated balance sheet totals at the beginning and the end of the financial year and we approximate the gross return $x \cdot I_{0}$ by the sum of EBIT and invested capital. The normalized gross return thus calculates to $x=\frac{\text { EBIT }}{\text { average balance sheet total }}+1$.

We use empirical data from the Dafne database (Bureau van Dijk) to feed our simulation model's gross return variable $x$. In accordance with the empirical riskfree interest data, we select accounting data from the financial year 2012. The database contains individual financial accounting data (German GAAP) from German companies in 21 industrial sectors. We select only individual financial statements from corporations following German Commercial Code (HGB) and remove records with missing EBITDA data or balance sheet totals. We further remove the public administration and defense sector, the sector of households as employers, as well as extraterritorial organizations and also records with missing industry code. The final sample contains 43,108 observations in 18 sectors. For descriptives on legal form and size (balance sheet totals as of 2012) refer to Table 1.

We winsorize large values of $x$ at the $1 \%$ percentile and set negative values to zero. In our single-period modeling, a company cannot lose more than the initially

Table 1 Descriptives on the applied data set

\begin{tabular}{|c|c|c|c|c|c|}
\hline \multirow[t]{2}{*}{ Legal form } & \multirow[t]{2}{*}{ Obs. } & & \multicolumn{3}{|c|}{ Total assets in million Euro } \\
\hline & & & Mean & Median & SD \\
\hline GmbH (limited liability corporations) & 40,574 & $94 \%$ & 36 & 2.7 & 410 \\
\hline AG (stock corporations) & 2,167 & $5 \%$ & 1,062 & 18.3 & 10,442 \\
\hline Other & 367 & $1 \%$ & 1,041 & 0.2 & 8,463 \\
\hline Total & 43,108 & $100 \%$ & & & \\
\hline
\end{tabular}




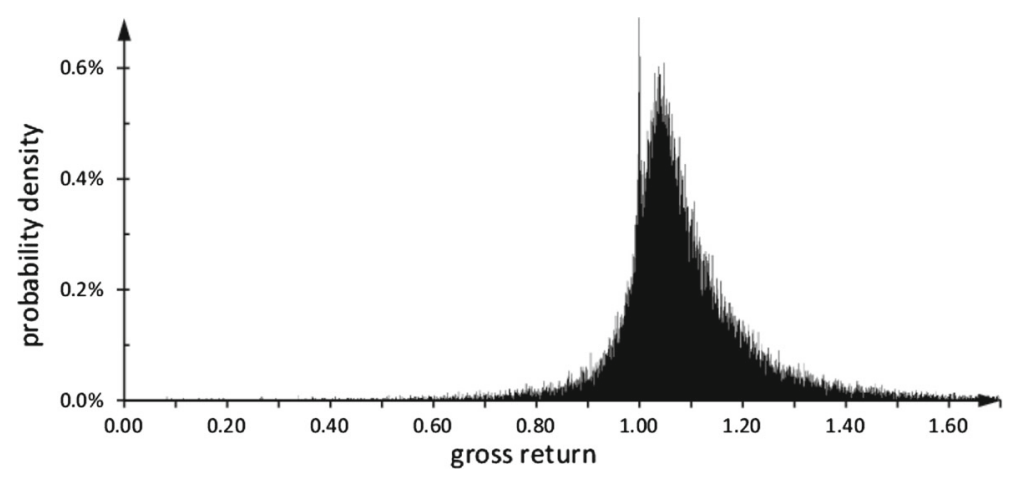

Fig. 5 Density curve of empirical gross return $x$

invested amount, while in a multi-period setting, each single period's cash flow can well be negative. The resulting distribution has a mean value of $\mu \approx 1.08$ and a standard deviation of $\sigma \approx 17.41 \%$. Figure 5 shows the distribution's density curve with data from 2012.

\subsection{Leverage-based IDR}

We perform the simulation with varying parameter combinations and measure the corporation's tax advantage, cta, defined as the difference between the partnership's and the corporation's expected total tax burden, including shareholder level tax.

Consequently, we repeat each analysis with the alteration that the IDR is introduced in a model world with an existing loss offset restriction on corporate level. The reference point for legal form dependent effects is the adjusted baseline model where the LOR is already in effect: we consider only tax differences caused by the IDR on top of the LOR. The target function is thus the corporation's net tax advantage, cnta, which is net of the LOR's tax effect.

Influence from leverage. With an $\alpha$ parameter of 1.5, the leverage-based IDR is binding for leverage above the binding threshold of $\lambda_{0}=60 \%$. We first vary the leverage parameter $\lambda$, keeping the remaining parameters constant, and describe the corporation's tax advantage, cta, as a continuous function of $\lambda$. With increasing $\lambda$ above the binding threshold, we find $\operatorname{cta}(\lambda)$ typically first increase, then decrease, eventually becoming negative. The function has at most one change of sign at the critical leverage, $\lambda_{\text {crit }}$. It is positive for $\lambda<\lambda_{\text {crit }}$ and negative for $\lambda>\lambda_{\text {crit }}$. This is because the dividend effect increases linearly in $\lambda$, while the default gain effect exhibits exponential shape. It usually starts weaker than the dividend effect and eventually approaches or surpasses it, as illustrated in Fig. 6. There is at most one point of intersection at $\lambda=\lambda_{\text {crit }}$.

The picture remains essentially unchanged when different parameter values for the risk-free interest rate are applied or data samples with varying risk are used. Changing these parameters, $\lambda_{\text {crit }}$ moves either left or right in the graph. The function $\operatorname{cta}(\lambda)$ may become strictly positive or strictly negative for all $\lambda>\lambda_{0}$, if the critical leverage moves right or left out of the domain of definition. 


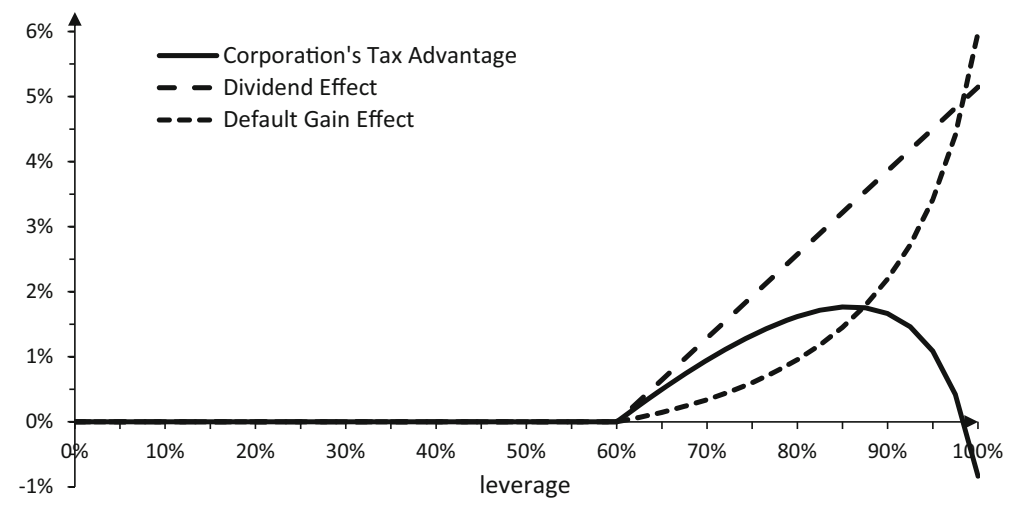

Fig. 6 Intersection of dividend effect and default gain effect. (data from 2012) Tax effects depicted over leverage. Effects are scaled as ratios of raw profit. The corporation's tax advantage calculates as the difference of the dividend effect and the default gain effect

Fig. 7 Influence from LOR. Illustrated is the corporation's net tax advantage with full loss offset and with LOR on corporate level

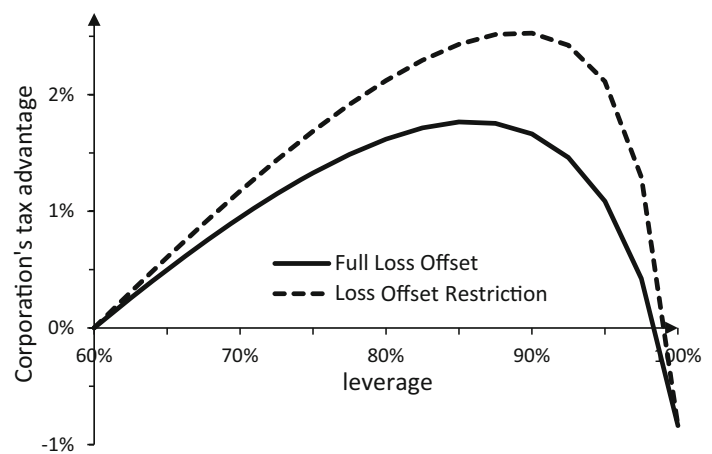

To test for robustness, we conduct the analysis with data for the financial years 2008 through 2012 as well as with a combined data set built from data using all five years, and we do this with risk-free interest rates taken from default-free zero coupon bonds with term to maturity of 1 year, 5, 10 and 30 years. Lastly, we run the analysis on sub-samples for each of the contained industries, each of which exhibits a different average gross return and standard deviation. The results remain qualitatively unchanged.

Influence from LOR. The graph of $\operatorname{cnta}(\lambda)$ exhibits visually the same shape as $\operatorname{cta}(\lambda)$, but the critical leverage is for most parameter combinations slightly larger when an LOR is effective, enlarging the range of possible $\lambda$ where the corporation is privileged (Fig. 7). The main effect is that in events of loss, the IDR cannot affect the corporation, as the tax base is already negative and the due tax amount tight to zero by the LOR, but the IDR unchangedly affects the partnership, increasing the corporation's net tax advantage cnta (interaction effect). In some cases (not illustrated in this figure), this effect can be compensated by an increase in the default gain effect, refer to Sect. 4.2. Figure 7 depicts the relative advantage for a 


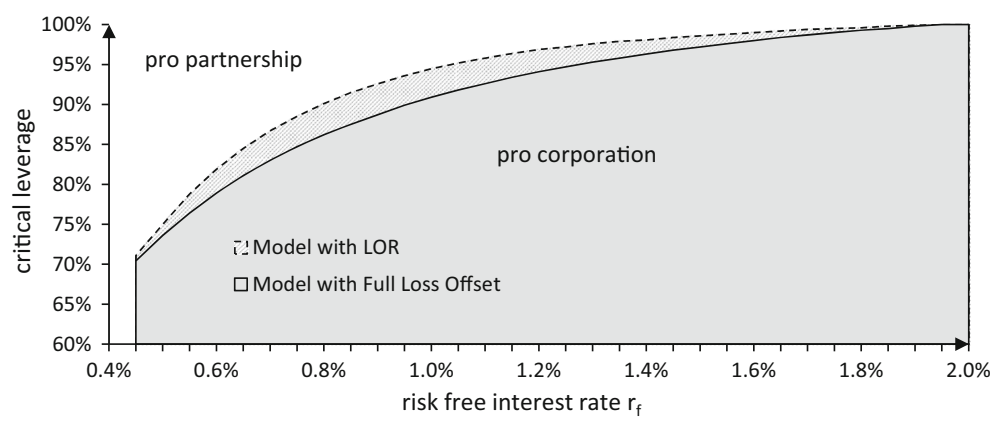

Fig. 8 Influence from risk-free interest

corporation caused by the IDR (rather than the absolute advantage) taking the adjusted baseline model as the reference where the LOR is already effective.

Influence from risk-free interest. A larger risk-free interest rate $r_{f}$ has an increasing impact on the critical leverage $\lambda_{\text {crit }}$. We vary $r_{f}$ from 0 to $2 \%$ and determine the resulting critical leverage. Figure 8 suggests $\lambda_{\text {crit }}$ being homogenous in $r_{f}$ with degree between zero and one. This picture does not change when an LOR is assumed, only the critical leverage values are slightly larger. Note that $\lambda_{\text {crit }}$ is defined only for an interval of $r_{f}$ and would extend to values $>100 \%$ for larger $r_{f}$ and to values $<\lambda_{0}$ for smaller $r_{f}$. If $r_{f}=0$, the partnership is advantageous for any $\lambda>\lambda_{0}$, and the IDR cannot bind for $\lambda \leq \lambda_{0}$. There is thus no critical leverage defined in this case.

If $r_{f}=0$, the partnership pays no interest and is, therefore, not affected by the IDR. The corporation pays a risk premium and is negatively affected by the IDR if $\lambda>\lambda_{0}$, which is why the corporation is discriminated against for small $r_{f}$. As $r_{f}$ increases, the dividend effect increases (pro corporation) and the default gain effect remains constant, depending only on $\lambda$. If $r_{f}$ is sufficiently large, $\lambda$ looses its influence and the corporation is always privileged, because $\lambda$ is restricted to the interval $[0,1]$, the default gain effect is, therefore, too, bounded above and is eventually dominated by the unrestricted dividend effect for large $r_{f}$. For medium $r_{f}$, the default gain effect can compensate the dividend effect if $\lambda$ is sufficiently large. The critical leverage is thus increasing in $r_{f}$ and enlarges the range of possible $\lambda$ where the corporation is advantageous.

Influence from risk. Working with the full sample of all industries, we vary the distributions' standard deviation by applying a mean-preserving spread to each $x$ value. (Note that this method works well with spread-reducing factors $<1$, but does not with spread-amplifying factors $>1$ as the resulting distribution would obtain negative cash flow values, contrary to the model assumptions.)

We find that risk seems to have a negative impact on the corporation's tax advantage, reducing the critical leverage. This is because the dividend effect is independent from risk, whereas the default gain effect is a multiple of the expected default gain. That is why the distribution of cash flows below the critical cash flow $x_{\mathrm{DG}}$ does and that above $x_{\mathrm{DG}}$ does not affect $\operatorname{cta}(\lambda)$ and $\lambda_{\text {crit }}$. The greater the investment's risk, the greater is in general the probability of a default gain, 


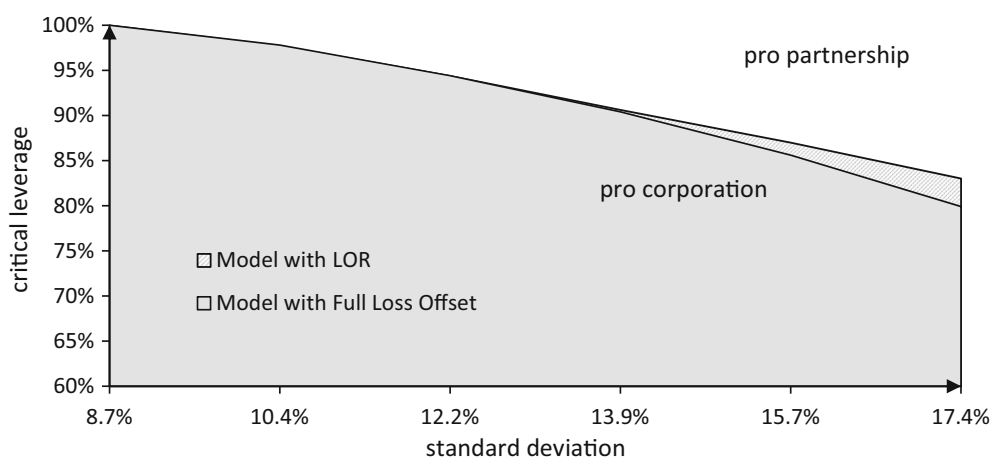

Fig. 9 Influence from risk

$P\left(x<x_{\text {DG }}\right)$, as well as the expected amount of default gain if one occurs. The default gain effect acts in the manner of a tax on default gains. If risk is low and $P\left(x<x_{\mathrm{DG}}\right)=0$, the default gain effect vanishes and due to the dividend effect, the corporation is privileged for any $\lambda$. Figure 9 shows the relation between the cash flow distribution's standard deviation and $\lambda_{\text {crit }}$.

\subsection{EBITDA-based IDR}

The EBITDA-based IDR is in a number of cases only binding for the partnership, but not for the corporation. As compared to the leverage-based IDR, the EBITDAbased IDR thus more often discriminates against the partnership. The reason is that the IDR can only bind when leverage is high and EBITDA is small, such that $30 \% \cdot$ EBITDA $<\lambda \cdot i$. The greater the leverage and the smaller the EBITDA, however, the greater is the corporation's probability of default, the smaller is the interest actually paid and the smaller is the chance that the IDR is at all binding for the corporation. Opposed to that, the partnership always pays full interest and is, therefore, mostly hit by the IDR in events of loss. When introduced on top of an existing loss offset restriction, this effect is a little less pronounced: the LOR increases the risky interest rate $i$ demanded by creditors, thereby increasing the IDR's upper binding bound $x_{2 u}=\frac{\lambda i}{30 \%}$, moving it closer to the cash flow distribution's peak value. This increases the chance that the IDR is binding for a corporation.

As with the leverage-based IDR, an increasing risk-free interest rate is usually pro corporation: A larger risk-free interest rate $r_{f}$ increases both the due and the paid interest amount and increases the chance that the IDR binds for both legal forms. The effect is usually stronger for the partnership, thus increasing the corporation's tax advantage, for relevant parameter combinations.

Contrary to the leverage-based IDR, a greater standard deviation in the distribution of cash flows increased the corporation's advantage in the analyzed scenarios. This has no effect on the critical leverage, however, as corporations are privileged for any leverage in these cases. 


\section{Conclusion}

Previous research shows the effects of IDR on firms' leverage ratios and investment policies but almost completely neglects the effect on the choice of organizational form. We show that both forms of IDR-leverage based as well as EBITDA based-generally distort the choice of organizational form. Only under very specific assumptions, i.e., full loss offset, symmetric taxation of default gains and interest, and either legal form specific IDR parameters or absence of dividend taxation, a leverage-based IDR is neutral to the choice of organizational form. A summary of the results regarding the leverage-based IDR under full loss offset is provided in Table 2.

The effect of the EBITDA-based IDR on the organizational form depends on the cash flow distribution and is, therefore, theoretically undetermined. Moreover, if we assume corporate loss offset restrictions, both forms of IDR always distort the decision between limited and unlimited liability firms. The effect of corporate loss offset restrictions is threefold: first, due to the missing loss offset for corporations, IDR are ineffective in case of losses. This privileges the corporation. Second, a tax exemption of a default gain that could compensate for the restricted interest deductibility is not effective due to the missing loss offset. Third, due to the missing loss offset, creditors will receive lower payments in the case of insolvency. This increases the expected default gain and the risk premium. This in turn leads to a higher effect of the IDR. In contrast to the first effect, the other two effects discriminate against the corporation. Thus, the total effect is undetermined and depends on the distribution of the cash flows, the leverage ratio, and the risk-free interest rates as we additionally illustrate in Monte Carlo simulations.

The policy implications are obvious: if legislators aim to achieve organizational form neutrality, this aim is generally in conflict with the introduction of IDR even if a uniform treatment of organizational forms with respect to IDR (such as is implemented in many countries) is applied. Also note that although we restrict our analysis to only two forms of IDR, the leverage-based IDR is in fact comparable to a proportional limitation of interest deductibility such as is used, e.g., in Germany for trade tax purposes. For any given debt ratio one can show the identity of proportional restrictions and leverage-based IDR. Additionally, while our model covers only third-party debt it could easily be extended to internal debt. Many IDR treat payments on internal debt as constructive dividends. In these cases our results

Table 2 Results for leverage-based interest deduction restrictions

\begin{tabular}{lll}
\hline Treatment of default gains and interest payments & Dividend taxation & Advantaged legal form \\
\hline Symmetric $(\beta=\alpha)$ & $=0$ & Neutral \\
Symmetric $(\beta=\alpha)$ & $>0$ & Corporation \\
Symmetric, legal form specific parameters & $>0$ & Neutral \\
$\beta>\alpha$ & $\geq 0$ & Corporation \\
$\beta<\alpha$ & $=0$ & Partnership \\
$\beta<\alpha$ & $>0$ & Distribution dependent \\
\hline
\end{tabular}


hold if (1) the tax rate on dividends equals the tax rate on interest revenues, (2) the interest rate equals the arm's length interest rate, and (3) losses due to a debtor's default are fully tax deductible at the same tax rate as interest payments. The last two conditions ensure the creditor's calculus to remain unchanged and the first one implies that one can neglect tax effects on shareholder level caused by constructive dividends.

From a tax research perspective it is worth to mention that future studies investigating organizational from neutrality of tax systems should consider that different legal forms face different liability rules and a uniform application of tax rules may, thus, be inappropriate to achieve organizational form neutrality. Furthermore, our results are also relevant for the discussion of the tax effect on the amount of collateral a shareholder should offer to the creditors of his or her corporation. Often corporations are de facto not limited in their liability, but, on the contrary, their owners offer personal guarantees to receive a loan for the firm. Then, the assumptions on liability differences among the organizational forms in this paper do not hold. However, our findings then apply for the owners' decision to offer a guarantee to the creditors or not-again a choice between limited and unlimited liability. The only difference is that in this case we would not have a dividend effect so that only the default gain effect remains. Therefore, one can conclude that IDR also distort the owners decision to offer collateral if default gains and interest payments are treated asymmetrically. Table 2 shows that legal rules that restrict the deductibility of interest expenses, but fully tax default gains $\left(\alpha^{\prime}>\beta^{\prime}\right)$ such as, e.g., the current tax regime in Germany provides an incentive to secure a loan by offering collateral.

Of course the used model is subject to some limitations. Most important, we only used a single-period model with no information asymmetries between borrowers and lenders. In our opinion this is sufficient to show the main effects of IDR on the choice of organizational form. In addition, we assumed that earnings before interest, taxes, depreciation, and amortization do not depend on the legal form. This neglects the fact that the legal form decision may affect risk taking and, therefore, cash flows. However, since our focus is on tax non-neutrality to the legal form decision, we believe our point gets clearer when holding all other decisions constant, including the investment decision, switching only the legal form. Moreover, the choice of legal form affects the risk taking of managers only if creditors cannot perfectly monitor the corporate activities which is in contrast to our assumption of symmetric information. In sum, it seems useful to expand the model to a multi-period setting in future research and maybe also to incorporate behavioral uncertainties resulting from information asymmetry.

Acknowledgments The authors gratefully acknowledge the helpful comments of Rainer Niemann (editor) and two anonymous reviewers.

Open Access This article is distributed under the terms of the Creative Commons Attribution License which permits any use, distribution, and reproduction in any medium, provided the original author(s) and the source are credited. 


\section{Appendix: Omitted proofs}

Proof of Lemma 1 We define the expected increase in corporate income tax caused by the proportional IDR as

$$
E\left[\Delta T_{\text {cit } 1}(x)\right]:=E\left[T_{\text {cit1 }}(x)\right]-E\left[T_{\text {cit }}(x)\right],
$$

where $T_{\text {cit } 1}(x)$ and $T_{\text {cit }}(x)$ are the corporation's tax payments with and without the IDR in effect,

$$
\begin{gathered}
T_{\text {cit }}(x):=\tau_{\text {cit }}\left(x-1-\left(D_{c}(x)-\lambda\right)\right), \text { and } \\
T_{\text {cit } 1}(x):=\tau_{\text {cit }}\left(x-1-\left(D_{c 1}(x)-\lambda\right)\right)+\tau_{\text {cit }} \operatorname{IDR}_{1}(x),
\end{gathered}
$$

with $\operatorname{IDR}_{1}(x)$ from Definition (12). Using $E\left[D_{c 1}(x)\right]=E\left[D_{c}(x)\right]$, one obtains

$$
E\left[T_{\mathrm{cit} 1}(x)\right]=\underbrace{\tau_{\mathrm{cit}} E\left[x-1-\left(D_{c 1}(x)-\lambda\right)\right]}_{=E\left[T_{\mathrm{cit}}(x)\right]}+\tau_{\mathrm{cit}} E\left[\operatorname{IDR}_{1}(x)\right]
$$

and thus

$$
E\left[\Delta T_{\text {cit } 1}(x)\right]=\tau_{\text {cit }} E\left[\operatorname{IDR}_{1}(x)\right] .
$$

The increase in tax burden on corporate level leads to an equally large decrease in dividend payment and in consequence to a decrease in shareholder level tax, such that

$$
E\left[\Delta T_{c 1}(x)\right]=E\left[\left(1-\tau_{s}\right) \Delta T_{\mathrm{cit} 1}(x)\right]=\left(1-\tau_{s}\right) \tau_{\mathrm{cit}} E\left[\operatorname{IDR}_{1}(x)\right]
$$

where

$$
E\left[\operatorname{IDR}_{1}(x)\right]=\int_{x_{\mathrm{DG}}}^{\infty} \alpha^{\prime}\left(D_{c 1}(x)-\lambda\right) f(x) \mathrm{d} x+\int_{0}^{x_{\mathrm{DG}}} \beta^{\prime}\left(D_{c 1}(x)-\lambda\right) f(x) \mathrm{d} x,
$$

with probability density function $f(x)$.

Rearranging and using $\left(1-\tau_{s}\right) \tau_{\text {cit }}=\tau-\tau_{s}$ leads to

$$
\begin{aligned}
E\left[\Delta T_{c 1}(x)\right] & =\left(\tau-\tau_{s}\right)\left(\alpha^{\prime} \int_{0}^{\infty}\left(D_{c 1}(x)-\lambda\right) f(x) \mathrm{d} x+\left(\beta^{\prime}-\alpha^{\prime}\right) \int_{0}^{x_{\mathrm{DG}}}\left(D_{c 1}(x)-\lambda\right) f(x) \mathrm{d} x\right) \\
& =\left(\tau-\tau_{s}\right) \alpha^{\prime}\left(E\left[D_{c 1}(x)\right]-\lambda\right)+\left(1-\tau_{s}\right) \tau_{\mathrm{cit}}\left(\beta^{\prime}-\alpha^{\prime}\right) \int_{0}^{x_{\mathrm{DG}}}\left(D_{c 1}(x)-\lambda\right) f(x) \mathrm{d} x .
\end{aligned}
$$

Substituting $E\left[D_{c 1}(x)\right]-\lambda=\lambda r_{f}$ from condition (3) yields (13).

Proof of Lemma 2 For $x=x_{\mathrm{DG}}$, we have $D_{c 1}(x)=x-T_{\text {cit } 1}(x)=\lambda$ and we know from definition (12) that $\operatorname{IDR}_{1}\left(x_{\mathrm{DG}}\right)=0$, therefore, 


$$
\begin{aligned}
T_{\mathrm{cit} 1}\left(x_{\mathrm{DG}}\right) & =\tau_{\mathrm{cit}}\left(x_{\mathrm{DG}}-1-\left(D_{c 1}\left(x_{\mathrm{DG}}\right)-\lambda\right)\right)+0 \\
& =\tau_{\mathrm{cit}}\left(x_{\mathrm{DG}}-1-\left(x_{\mathrm{DG}}-T_{\mathrm{cit} 1}\left(x_{\mathrm{DG}}\right)-\lambda\right)\right) \\
& =-\tau_{\mathrm{cit}}(1-\lambda)+\tau_{\mathrm{cit}} T_{\mathrm{cit} 1}\left(x_{\mathrm{DG}}\right) \\
& =-\frac{\tau_{\mathrm{cit}}}{1-\tau_{\mathrm{cit}}}(1-\lambda) \\
\text { and } \quad x_{\mathrm{DG}} & =\lambda+T_{\mathrm{cit} 1}\left(x_{\mathrm{DG}}\right)=\lambda-\frac{\tau_{\mathrm{cit}}}{1-\tau_{\mathrm{cit}}} \cdot(1-\lambda) .
\end{aligned}
$$

For $x \leq x_{\mathrm{DG}}$, we have $D_{c 1}(x)=x-T_{\text {cit } 1}(x)$ and $\operatorname{IDR}_{1}(x)=\beta^{\prime}\left(D_{c 1}(x)-\lambda\right)$, therefore,

$$
\begin{aligned}
T_{\text {cit } 1}(x) & =\tau_{\text {cit }}\left(x-1-\left(D_{c 1}(x)-\lambda\right)\right)+\tau_{\text {cit }} \beta^{\prime}\left(D_{c 1}(x)-\lambda\right) \\
& =\tau_{\text {cit }}\left(x-1-\left(x-T_{\text {cit } 1}(x)-\lambda\right)\right)+\tau_{\text {cit }} \beta^{\prime}\left(x-T_{\text {cit } 1}(x)-\lambda\right) \\
& =\tau_{\text {cit }}\left(-(1-\lambda)+\beta^{\prime}(x-\lambda)\right)+\tau_{\text {cit }}\left(1-\beta^{\prime}\right) T_{\text {cit } 1}(x) \\
& =-\theta_{\beta 1}\left(1-\lambda-\beta^{\prime}(x-\lambda)\right) \quad \forall x \leq x_{\mathrm{DG}}
\end{aligned}
$$

$$
\text { and } \quad D_{c 1}(x)=x+\theta_{\beta 1}(1-\lambda-\beta(x-\lambda)) \quad \forall x \leq x_{\mathrm{DG}},
$$

$$
\text { where } \theta_{\beta 1}:=\frac{\tau_{\text {cit }}}{1-\tau_{\text {cit }}\left(1-\beta^{\prime}\right)} \text {. }
$$

Applying (51) and (53) in (22), we can resolve the default gain expectancy:

$$
\begin{aligned}
\mathrm{EDG} & =\int_{0}^{x_{\mathrm{DG}}}\left(D_{c 1}(x)-\lambda\right) f(x) \mathrm{d} x=\int_{0}^{x_{\mathrm{DG}}}\left(x+\theta_{\beta 1}\left(1-\lambda-(x-\lambda) \beta^{\prime}\right)-\lambda\right) f(x) \mathrm{d} x \\
& =\int_{0}^{x_{\mathrm{DG}}}(x+\theta_{\beta 1}\left(x_{\mathrm{DG}}-x\right) \beta^{\prime}-\underbrace{\left(\lambda-\theta_{\beta 1} \cdot\left(1-\lambda-\left(x_{\mathrm{DG}}-\lambda\right) \beta^{\prime}\right)\right)}_{=\lambda+T_{\mathrm{cit1}}\left(x_{\mathrm{DG}}\right)=x_{\mathrm{DG}}}) f(x) \mathrm{d} x \\
& =\int_{0}^{x_{\mathrm{DG}}}\left(x\left(1-\theta_{\beta 1} \beta^{\prime}\right)-x_{\mathrm{DG}}\left(1-\theta_{\beta 1} \beta^{\prime}\right)\right) f(x) \mathrm{d} x \\
& =\left(1-\theta_{\beta 1} \beta^{\prime}\right) \cdot \int_{0}^{x_{\mathrm{DG}}} x f(x) \mathrm{d} x-x_{\mathrm{DG}}\left(1-\theta_{\beta 1} \beta^{\prime}\right) \cdot \int_{0}^{x_{\mathrm{DG}}} f(x) \mathrm{d} x \\
& =-\frac{1-\tau_{\mathrm{cit}}}{1-\tau_{\mathrm{cit}}\left(1-\beta^{\prime}\right)} \cdot\left(x_{\mathrm{DG}}-E\left[x \mid x<x_{\mathrm{DG}}\right]\right) \cdot P\left(x<x_{\mathrm{DG}}\right) .
\end{aligned}
$$

Applying (55) in (21) yields (23).

Proof of Lemma 3 Solving (26) yields $T_{\text {cit } 2}(x)=\tau_{\text {cit }}(x-1-\gamma x), \forall x \in\left(x_{2 l}, x_{2 u}\right)$, and using this as well as $\operatorname{IDR}_{2}\left(x_{2 l}\right)=\operatorname{IDR}_{2}\left(x_{2 u}\right)=0$ in $D_{c 2}(x)=$ $\left\{\begin{array}{ll}x-T_{\text {cit } 2}(x), & \text { if } x<x_{2}, \\ \lambda(1+i), & \text { else, }\end{array}\right.$ results in 


$$
\begin{aligned}
\operatorname{IDR}_{2}(x) & = \begin{cases}x-\tau_{\text {cit }}(x-1-\gamma x)-\lambda-\gamma x, & \text { if } x_{2 l} \leq x<x_{2}, \\
\lambda i-\gamma x, & \text { if } x_{2} \leq x \leq x_{2 u},\end{cases} \\
& = \begin{cases}x\left(1-\tau_{\text {cit }}\right)(1-\gamma)-\left(\lambda-\tau_{\text {cit }}\right), & \text { if } x_{2 l} \leq x<x_{2}, \\
\lambda i-\gamma x, & \text { if } x_{2} \leq x \leq x_{2 u},\end{cases}
\end{aligned}
$$

To obtain $x_{2 l}$, set $\operatorname{IDR}_{2}\left(x_{2 l}\right) \stackrel{!}{=} 0$ and find that $x_{2 l}=\frac{\lambda-\tau_{\text {cit }}}{\left(1-\tau_{\text {cit }}\right)(1-\gamma)}$.

This allows direct calculation of $E\left[\operatorname{IDR}_{2}(x)\right]$ as follows:

$$
\begin{aligned}
E\left[\operatorname{IDR}_{2}(x)\right] & =\int_{0}^{\infty} \operatorname{IDR}_{2}(x) f(x) \mathrm{d} x=\int_{x_{2 l}}^{x_{2 u}}\left(D_{c 2}(x)-\lambda-\gamma x\right) f(x) \mathrm{d} x \\
& =\int_{x_{2 l}}^{x_{2}}\left(1-\tau_{\text {cit }}\right)(1-\gamma)\left(x-\frac{\lambda-\tau_{\text {cit }}}{\left(1-\tau_{\text {cit }}\right)(1-\gamma)}\right) f(x) \mathrm{d} x+\int_{x_{2}}^{x_{2 u}}(\lambda i-\gamma x) f(x) \mathrm{d} x \\
& =\int_{x_{2 l}}^{x_{2}}\left(x-x_{2 l}\right)\left(1-\tau_{\text {cit }}\right)(1-\gamma) f(x) \mathrm{d} x+\int_{x_{2}}^{x_{2 u}}(\lambda i-\gamma x) f(x) \mathrm{d} x
\end{aligned}
$$

Proof of Lemma 4 To see (39), rewrite (38) to

$$
T_{\text {cit } 1 *}(x)=\tau_{\text {cit }}\left(x-1-\left(D_{c 1 *}(x)-\lambda\right)\right)+\tau_{\text {cit }} \operatorname{IDR}_{1 *}(x)+\tau_{\text {cit }} L \operatorname{OR}_{1 *}(x)
$$

where

$$
\begin{aligned}
\operatorname{IDR}_{1 *}(x) & = \begin{cases}\alpha^{\prime}\left(D_{c 1 *}(x)-\lambda\right), & x \geq \lambda, \\
\beta^{\prime}\left(D_{c 1 *}(x)-\lambda\right), & x<\lambda,\end{cases} \\
& =\alpha^{\prime}\left(D_{c 1 *}(x)-\lambda\right)+ \begin{cases}0, & x \geq \lambda, \\
\left(\beta^{\prime}-\alpha^{\prime}\right)(x-\lambda), & x<\lambda,\end{cases}
\end{aligned}
$$

and

$$
\operatorname{LOR}_{1 *}(x)=\left\{\begin{array}{cc}
-T(x), & x \leq x_{1 * *}, \\
0, & \text { else, }
\end{array}=\left\{\begin{array}{cc}
0, & x \geq x_{1 * *}, \\
1-\lambda-\beta^{\prime}(x-\lambda), & x \leq \lambda, \\
1-\lambda-\alpha^{\prime}(x-\lambda), & \lambda<x \leq \min \left\{x_{1 *}, x_{1 * *}\right\}, \\
1+\left(1-\alpha^{\prime}\right) \lambda i-x, & \min \left\{x_{1 *}, x_{1 * *}\right\}<x<x_{t 1 *} .
\end{array}\right.\right.
$$

Taking expectancies in (58) yields the expected change in corporate income tax,

$$
E\left[\Delta T_{\mathrm{cit} 1 *}(x)\right]=E\left[T_{\mathrm{cit} 1 *}(x)\right]-E\left[T_{\mathrm{cit}}(x)\right]=\tau_{\mathrm{cit}} E\left[\operatorname{IDR}_{1 *}(x)\right]+\tau_{\mathrm{cit}} E\left[\operatorname{LOR}_{1 *}(x)\right],
$$

and multiplying with $\left(1-\tau_{s}\right)$ yields the expected change in total tax, 


$$
\begin{aligned}
E\left[\Delta T_{c 1 *}(x)\right] & =\left(1-\tau_{s}\right) E\left[\Delta T_{\text {cit } 1 *}(x)\right] \\
& =\left(1-\tau_{s}\right) \tau_{\mathrm{cit}} E\left[\operatorname{IDR}_{1} 1 *(x)+\operatorname{LOR}_{1 *}(x)\right] \\
& =\left(\tau-\tau_{s}\right) E\left[\operatorname{IDR}_{1 *}(x)+\operatorname{LOR}_{1 *}(x)\right] \\
& =\left(\tau-\tau_{s}\right)[\alpha^{\prime} \lambda r_{f}+\int_{0}^{m} \underbrace{\left(1-\lambda-\alpha^{\prime}(x-\lambda)\right)}_{>0} f(x) \mathrm{d} x+\int_{m}^{x_{1+*}} \underbrace{\left(x_{1 t *}-x\right)}_{\geq 0} f(x) \mathrm{d} x] . \\
& =: \text { AT }- \text { div_effect }+ \text { residual }
\end{aligned}
$$

where $m=\min \left\{x_{1 *}, x_{1 * *}\right\}, \mathrm{AT}=\tau \alpha^{\prime} \lambda r_{f}$ and div_effect $=\tau_{s} \alpha^{\prime} \lambda r_{f}$.

The residual in (62) makes up the DG effect, the LOR effect and an interaction effect. To analyze these, two cases must be distinguished: The risky interest rate $i$ demanded by creditors is affected by the IDR if and only if $x_{1 * *}<x_{1 *}$, i.e., if corporate income tax can be positive in a default scenario and, therefore, further reduce debt service. To obtain $x_{1 *}$, set $D_{c 1 *}\left(x_{1 *}\right)=\lambda(1+i)=x_{1 *}-T_{\text {cit } 1 *}\left(x_{1 *}\right)$, which solves to $x_{1 *}=\lambda(1+i)+T_{\text {cit } 1 *}\left(x_{1 *}\right)$. Using this in definition (38) yields $t_{1 *}\left(x_{1 *}\right)=$ $\tau_{\text {cit }}\left(x_{1 *}-1-\left(1-\alpha^{\prime}\right) \lambda i\right)=\tau_{\text {cit }}\left(\lambda(1+i)+T_{\text {cit } 1 *}\left(x_{1 *}\right)-1-\left(1-\alpha^{\prime}\right) \lambda i\right)=\tau_{\text {cit }} T_{\text {cit } 1 *}$ $\left(x_{1 *}\right)+\tau_{\text {cit }}\left(\alpha^{\prime} \lambda i-(1-\lambda)\right)$. Now note that $t_{1 *}$ and $T_{\text {cit } 1 *}$ are equal if $t_{1 *}$ is positive and $T_{\text {cit } 1 *}=0$ if $t_{1 *}$ is negative. Thus:

$$
\begin{aligned}
t_{1 *}\left(x_{1 *}\right) \leq 0 & \Rightarrow t_{1 *}\left(x_{1 *}\right)=0+\tau_{\mathrm{cit}}\left(\alpha^{\prime} \lambda i-(1-\lambda)\right) \Rightarrow \alpha^{\prime} \lambda i \leq 1-\lambda \\
t_{1 *}\left(x_{1 *}\right)>0 & \Rightarrow T_{\mathrm{cit} 1 *}\left(x_{1 *}\right)=t_{1 *}\left(x_{1 *}\right)=\tau_{\mathrm{cit}} t_{1 *}\left(x_{1 *}\right)+\tau_{\mathrm{cit}}\left(\alpha^{\prime} \lambda i-(1-\lambda)\right) \\
& =\frac{\tau_{\mathrm{cit}}}{1-\tau_{\mathrm{cit}}}\left(\alpha^{\prime} \lambda i-(1-\lambda)\right) \Rightarrow \alpha^{\prime} \lambda i>1-\lambda
\end{aligned}
$$

and taken together:

$$
x_{1 *}<x_{1 *} \Leftrightarrow t_{1 *}\left(x_{1 *}\right)>0 \Leftrightarrow \alpha^{\prime} \lambda i>1-\lambda .
$$

Only a strict non-deduction factor $\alpha^{\prime}$ combined with high leverage will thus affect the demanded interest rate. The intuition behind this result is that in case of cash flows just allowing full debt service $\left(x=x_{1 *}\right)$, the complete loss of equity $(1-\lambda)$ usually makes for a negative tax base, but can be compensated by the nondeductible interest $\left(\alpha^{\prime} \lambda i\right)$.

Case 1: If $\alpha^{\prime} \lambda i \leq 1-\lambda$, the residual in (62) is directly comparable to the LOR effect (34) in the adjusted baseline model, as the interest rate $i$ has the same value in both formulae, and the critical cash flow is $x_{1 *}=x_{1}=\lambda(1+i)$ in both models. To obtain $x_{1 t *}$, note that $T(x)>0 \Leftrightarrow x>1+\left(1-\alpha^{\prime}\right)\left(D_{c 1 *}(x)-\lambda\right)$, and thus $x_{1 * *}=1+\lambda i\left(1-\alpha^{\prime}\right)$. Subtracting the LOR effect as well as a DG effect with parameter $\beta^{\prime}=0$ yields 


$$
\begin{aligned}
& \text { interaction_effect }:=\text { residual }- \text { LOR_effect }- \text { DG_effect } \\
& \begin{array}{l}
=\left(\tau-\tau_{s}\right)\left[\int_{0}^{x_{1 *}}\left(1-\lambda-\alpha^{\prime}(x-\lambda)\right) f(x) \mathrm{d} x+\int_{x_{1 *}}^{x_{1 * *}}\left(x_{1 t *}-x\right) f(x) \mathrm{d} x\right. \\
\left.\quad-\int_{0}^{x_{1}}(1-\lambda) f(x) \mathrm{d} x-\int_{x_{1}}^{1+\lambda i}(1+\lambda i-x) f(x) \mathrm{d} x\right]- \text { DG_effect } \\
=-\left(\tau-\tau_{s}\right)[\alpha^{\prime} \int_{\lambda}^{x_{1 * *}} \underbrace{\left(D_{c 1 *}(x)-\lambda\right)}_{\geq 0} f(x) \mathrm{d} x+\int_{x_{1 * *}}^{1+\lambda i} \underbrace{(1+\lambda i-x)}_{\geq 0} f(x) \mathrm{d} x]<0
\end{array}
\end{aligned}
$$

Case 2: If $\alpha^{\prime} \lambda i>1-\lambda$, the above analysis remains true, except that the risky interest rate $i$ increases to $j>i$, compared to the adjusted baseline model, and that $x_{1 * *}=\lambda+\frac{1-\lambda}{\alpha^{\prime}}<x_{1}=\lambda(1+i)<\lambda(1+j)<x_{1 *}$. Subtraction yields

interaction_effect $:=$ residual - LOR_effect - DG_effect

$$
\begin{aligned}
& =\left(\tau-\tau_{s}\right)\left[\int_{0}^{x_{1 t *}}\left(1-\lambda-\alpha^{\prime}(x-\lambda)\right) f(x) \mathrm{d} x-\int_{0}^{x_{1}}(1-\lambda) f(x) \mathrm{d} x-\xi\right]-\text { DG_effect } \\
& =\left(\tau-\tau_{s}\right)\left[\int_{\lambda}^{x_{1 t *}}\left(1-\lambda-\alpha^{\prime}(x-\lambda)\right) f(x) \mathrm{d} x-\int_{\lambda}^{x_{1}}(1-\lambda) f(x) \mathrm{d} x-\xi\right] \\
& =-\left(\tau-\tau_{s}\right)[\int_{\lambda}^{x_{1 t *}} \underbrace{\alpha^{\prime}(x-\lambda)}_{\geq 0} f(x) \mathrm{d} x+\int_{x_{1 * *}}^{x_{1}} \underbrace{(1-\lambda)}_{\geq 0} f(x) \mathrm{d} x+\xi]<0,
\end{aligned}
$$

where $\xi:=\int_{x_{1}}^{1+\lambda i} \underbrace{(1+\lambda i-x)}_{\geq 0} f(x) \mathrm{d} x$.

Proof of Lemma 5 First, set $\operatorname{IDR}_{2 *}(x)=D_{c 2 *}(x)-\lambda-\gamma x \stackrel{!}{=} 0$, to obtain $x_{2 l *}=\frac{\lambda}{1-\gamma}$ and $x_{2 u *}=\frac{\lambda i}{\gamma}$, and rewrite the tariff function to

$$
t_{2 *}(x)=\tau_{\text {cit }} \begin{cases}x-1-\lambda i, & x \geq x_{2 u *,} \\ x(1-\gamma)-1, & x \in\left(x_{2 l *}, x_{2 u *}\right), \\ -(1-\lambda), & x \leq x_{2 l *} .\end{cases}
$$

The IDR can be effective at all only if $x_{t 2 *}<x_{2 u *}$. If so, setting $t_{2 *}\left(x_{t 2 *}\right)=$ $x_{t 2 *}(1-\gamma)-1 \stackrel{!}{=} 0$ yields $x_{t 2 *}=\frac{1}{1-\gamma}<x_{2 u *}=\frac{\lambda i}{\gamma}$. Otherwise, setting $t_{2 *}\left(x_{t 2 *}\right)=$ $x_{t 2 *}-1-\lambda i=0$ yields $x_{t 2 *}=1+\lambda i>x_{2 u *}=\frac{\lambda i}{\gamma}$. Taken together, one obtains $x_{t 2 *}<x_{2 u}$ if and only if $\frac{\gamma}{1-\gamma}<\lambda i$.

If $\frac{\gamma}{1-\gamma} \geq \lambda i$, the tax base is negative for all $x$ where the IDR is binding, 


$$
\left.\frac{t_{2 *}(x)}{\tau_{\mathrm{cit}}}\right|_{x \in\left(x_{1 *}, x_{2 u *}\right)}=x(1-\gamma)-1 \leq \frac{x \gamma}{\lambda i}-1<\frac{x_{2 u * \gamma}}{\lambda i}-1=0,
$$

the tax payment is thus zero due to the LOR, and the IDR not effective.

Proof of Lemma 6 A corporation defaults on debt service if $x<x_{2 *}$. Positive tax for any $x<x_{2 *}$ implies $T_{\text {cit } 2 *}\left(x_{2 *}\right)>0$, as the tariff function is monotonically increasing in $x$, and is, therefore, equivalent to $T\left(x_{2 *}\right)=x_{2 *}(1-\gamma)-1>0$ and to $x_{2 *}>\frac{1}{1-\gamma}$.

To obtain $x_{2 *}$, solve $D_{c 2 *}\left(x_{2 *}\right)=\lambda(1+i)=x_{2 *}-T_{\text {cit } 2 *}\left(x_{2 *}\right)$, which yields

$$
x_{2 *}=\lambda(1+i)+T_{\mathrm{cit} 2 *}\left(x_{2 *}\right),
$$

and if $T_{\text {cit } 2 *}\left(x_{2 *}\right)>0$ solves to $x_{2 *}=\frac{\lambda(1+i)-1}{\gamma}>\frac{1}{1-\gamma}$, which easily transforms to $\lambda(1+i)>\frac{1}{1-\gamma}$. Taken together, one can conclude

$$
\begin{aligned}
& T_{\text {cit* }}\left(x_{2 *}\right)>0 \Leftrightarrow \lambda(1+i)>\frac{1}{1-\gamma} \Leftrightarrow 1-\gamma>\frac{1}{\lambda(1+i)} \\
& \Leftrightarrow \gamma<1-\frac{1}{\lambda(1+i)}=\frac{i}{1+i}-\frac{1-\lambda}{\lambda(1+i)} \ll i .
\end{aligned}
$$

If on the contrary $\gamma>i$, the corporate income tax payment is zero for all $x \leq x_{2 *}$ and the IDR, therefore, not effective.

Proof of Lemma 7 Proposition 5 and Lemma 6 provide

$$
x_{2 *}=\lambda(1+i) \leq x_{2 t *}=\frac{1}{1-\gamma}<1+\lambda i<x_{2 u *}=\frac{\lambda i}{\gamma} .
$$

Rewriting (38) as $\quad T_{\text {cit } 2 *}(x)=\tau_{\text {cit }}\left(x-1-\left(D_{c 2 *}(x)-\lambda\right)\right)+\tau_{\text {cit }}\left(\operatorname{IDR}_{2 *}(\mathrm{x})+\right.$ $\left.\operatorname{LOR}_{2 *}(\mathrm{x})\right)$ yields

$$
\begin{aligned}
& \operatorname{IDR}_{2 *}(x)= \begin{cases}\lambda i-\gamma x, & x \in\left[x_{2 *}, x_{2 u *}\right), \\
x(1-\gamma)-\lambda, & x \in\left(x_{2 l *}, x_{2 *}\right), \\
0 & \text { else, }\end{cases} \\
& \operatorname{LOR}_{2 *}(x)= \begin{cases}0, & x \geq x_{2 t *}, \\
1-x(1-\gamma), & x \in\left(x_{2 l *}, x_{2 t *}\right), \\
1-\lambda, & x \leq x_{2 l *},\end{cases}
\end{aligned}
$$

In comparison to the baseline model without LOR and without IDR, the expected increase in corporate income tax is

$$
E\left[\Delta T_{\mathrm{cit} 2 *}(x)\right]=E\left[T_{\mathrm{cit} 2 *}(x)\right]-E\left[T_{\mathrm{cit}}(x)\right]=\tau_{\mathrm{cit}} E\left[\operatorname{IDR}_{2 *}(x)+\operatorname{LOR}_{2 *}(x)\right],
$$

and the expected increase in total tax burden is

$$
E\left[\Delta T_{c 2 *}(x)\right]=\left(1-\tau_{s}\right) E\left[\Delta T_{\mathrm{cit} 2 *}(x)\right]=\left(1-\tau_{s}\right) \tau_{\mathrm{cit}} E\left[\operatorname{IDR}_{2 *}(x)+\operatorname{LOR}_{2 *}(x)\right],
$$

where 


$$
\begin{aligned}
& E\left[\operatorname{IDR}_{2 *}(x)+\operatorname{LOR}_{2 *}(x)\right] \\
& =\int_{0}^{x_{2 *}}(1-\lambda) f(x) \mathrm{d} x+\int_{x_{2 *}}^{x_{2 t *}}(1+\lambda i-x) f(x) \mathrm{d} x+\int_{x_{2 t *}}^{x_{2 u *}}(\lambda i-\gamma x) f(x) \mathrm{d} x .
\end{aligned}
$$

To obtain the tax increase caused by the introduction of the IDR when the LOR is already present, the value of $E\left[\operatorname{LOR}_{*}(x)\right]$ from (35) must be subtracted, resulting in

$$
\begin{aligned}
& E\left[\operatorname{IDR}_{2 *}(x)+\operatorname{LOR}_{2 *}(x)-\operatorname{LOR}_{*}(x)\right] \\
& =\int_{x_{2 * *}}^{1+\lambda i} \underbrace{(x(1-\gamma)-1)}_{\geq 0} f(x) \mathrm{d} x+\int_{1+\lambda i}^{x_{2 u *}} \underbrace{(\lambda i-\gamma x)}_{\geq 0} f(x) \mathrm{d} x .
\end{aligned}
$$

\section{References}

Blaufus, Kay, and Jochen Hundsdoerfer. 2008. Taxes and the choice between risky and risk-free debt: on the neutrality of credit default taxation. Review of Managerial Science 2: 161-181.

Blaufus, Kay, and Britta Mantei. 2014. Taxes, risky investments, and the simultaneous choice of legal form and financing. Journal of Business Economics 84: 1111-1141.

Buettner, Thiess, Michael Overesch, Ulrich Schreiber and Georg Wamser. 2006. The impact of thincapitalization rules on multinationals' financing and investment decisions. CESifo working paper series, no. 1817 .

Buettner, Thiess, Michael Overesch, Ulrich Schreiber, and Georg Wamser. 2012. The impact of thincapitalization rules on the capital structure of multinational firms. Journal of Public Economics 96 : 930-938.

Buslei, Hermann, and Martin Simmler. 2012. The impact of introducing an interest barrier: evidence from the German corporation tax reform 2008. Discussion Papers: German Institute for Economic Research, DIW Berlin, No. 1215.

Dreßler, Daniel and Uwe Scheuering. 2012. Empirical evaluation of interest barrier effects. ZEWCentre for European Economic Research Discussion Paper (12-046).

Edmark, Karin, and Roger H. Gordon. 2013. The choice of organizational form by closely-held firms in Sweden: tax versus non-tax determinants. Industrial and Corporate Change 22: 219-243.

Elschner, Christina. 2013. Special tax regimes and the choice of organizational form: evidence from the European Tonnage Taxes. Journal of Public Economics 97: 206-216.

Ewert, Ralf, and Niemann Rainer. 2012. Limited liability, asymmetric taxation, and risk taking-why partial tax neutralities can be harmful. FinanzArchiv: Public Finance Analysis 68: 83-120.

Feld, Lars P., Jost H. Heckemeyer, and Michael Overesch. 2013. Capital structure choice and company taxation: a meta-study. Journal of Banking and Finance 37: 2850-2866.

Gravelle, Jane G., and Laurence J. Kotlikoff. 1993. Corporate tax incidence and inefficiency when corporate and noncorporate goods are close substitutes. Economic Inquiry 31: 501-516.

Goolsbee, Austan. 1998. Taxes, organizational form, and the deadweight loss of the corporate income tax. Journal of Public Economics 69: 143-152.

König, Rolf, Alexandra Maßbaum, and Caren Sureth. 2013. Besteuerung und Rechtsformwahl, 6, vollständig überarbeitete Auflage. Herne: Verlag Neue Wirtschafts-Briefe.

Luna, LeAnn, and Matthew N. Murray. 2010. The effects of state tax structure on business organizational form. National Tax Journal 63: 995-1022.

Maßbaum, Alexandra, Tasja Klotzkowski, and Caren Sureth. 2012. Der Einfluss der Zinsschranke auf unternehmerische Kapitalstrukturentscheidungen. Journal of Business Economics 82: 1389-1425. 
Maßbaum, Alexandra, and Caren Sureth. 2009. Thin capitalization rules and entrepreneurial capital structure decisions. BuR-Business Research 2: 147-169.

Miller, Merton H. 1977. Debt and Taxes. The Journal of Finance 32: 261-275.

Overesch, Michael, and Georg Wamser. 2010. Corporate tax planning and thin-capitalization rules: evidence from a quasi-experiment. Applied Economics 42: 563-573.

Schmidt, Olesja. 2010. Zinsschranke und Rechtsformwahl: Rechtsformspezifische Besonderheiten und Steuerbelastungsvergleich im Konzern. Kovač.

Wagner, Franz W. 2006. Was bedeutet und wozu dient Rechtsformneutralität der Besteuerung? Steuer und Wirtschaft 97: 101-114.

Webber, Stuart. 2010. Thin capitalization and interest deduction rules: a worldwide survey. Tax Notes International 60(9): 683-708. 